\title{
Timing and time perception: A review of recent behavioral and neuroscience findings and theoretical directions
}

\author{
Simon Grondin \\ Université Laval, Québec, Canada
}

\begin{abstract}
The aim of the present review article is to guide the reader through portions of the human time perception, or temporal processing, literature. After distinguishing the main contemporary issues related to time perception, the article focuses on the main findings and explanations that are available in the literature on explicit judgments about temporal intervals. The review emphasizes studies that are concerned with the processing of intervals lasting a few milliseconds to several seconds and covers studies issuing from either a behavioral or a neuroscience approach. It also discusses the question of whether there is an internal clock (pacemaker counter or oscillator device) that is dedicated to temporal processing and reports the main hypotheses regarding the involvement of biological structures in time perception.
\end{abstract}

Suppose someone had to prepare a review article on visual perception, instead of time perception. This individual would probably ask for a series of reviews, with at least one - and probably several - dedicated to color, distance, shape, and motion perception, and maybe to other aspects of visual perception. It would be very difficult to complete the same exercise for time perception since the categories of temporal experiences are not as clearly defined. However, for a reader to understand the scope of a text on time perception, it is essential to develop a representation of what the main research avenues or categories are. The present text should help the reader to grasp the scope of recent literature related to psychological time and time perception.

After a brief overview of the various perspectives on what could be meant by psychological time, the review will propose to identify of series of key concepts and empirical findings that should delineate the field of time perception and timing, and will discuss some models of time perception. The article also provides a review of the main recent findings in the field in which a neuroscientific approach to timing is adopted. In this section, the roles of the cerebellum, of the cerebral cortices, and of the basal ganglia in the timing processes are emphasized.

\section{Time Perception Beyond the Focus of the Present Review}

There is a wide range of research on psychological time and temporal processing, mainly because of the ubiquity of time in behavior and the relevance of a temporal perspective in regard to living organisms and events. There is a vast literature in social psychology as to how behavior is shaped by time (see Perret-Clermont, 2005, or Strathman \& Joireman, 2005), which includes topics such as time management, time perspective, and time orientation, or the relative value of past and future (Caruso, Gilbert, \& Wilson, 2008; Zimbardo \& Boyd, 1999). Even within the scope of experimental psychology, some studies have emphasized how the temporal structure of events determines our perception of the world (see the second part of Helfrich, 2003).

Some authors who are interested in consciousness have adopted a phenomenological perspective on time (see the first part of Buccheri, Saniga, \& Stuckey, 2003). Indeed, time and consciousness have become more closely linked recently with the development of a new area of research on the concept of chronesthesia (awareness of subjective time; Tulving, 2002), as opposed to noetic consciousness (awareness of the world) or autonoetic consciousness (awareness of self in time). Interestingly, there is now evidence that even animals can anticipate the future (Roberts, 2008).

There are many psychological time studies related in various ways to memory processes (Block \& Zakay, 2008). One research avenue deals with the chronology of events in our lives, particularly the memory of the order of occurrence of these events (Damasio, 2002; Friedman, 1993). Remembering in autobiographical memory when a past event occurred is different from remembering the duration

S. Grondin, simon.grondin@psy.ulaval.ca 
of an event or activity, which is defined below as "retrospective timing." Remembering a past event comprises two major processes. One is location based and consists of using contextual associations to judge how recent events are. The other process is distance based and involves estimating the amount of time that has elapsed between a past event and the present, or the relative recency of two past events. Another memory-related ability is known as prospective memory, or the ability to formulate plans and promises, to retain them, and to execute them in the future in the appropriate context, which may involve a time (e.g., 5:00 p.m.) or a specific amount of time (e.g., 5 min) (for time-based issues on prospective memory, see Glicksohn \& Myslobodsky, 2006; Labelle, Graf, Grondin, \& GagnéRoy, 2009). Finally, the capacity to estimate the duration of a future task is another ability based on memory (Roy \& Christenfeld, 2008; Roy, Christenfeld, \& McKenzie, 2005; Thomas, Handley, \& Newstead, 2007).

Other portions of the timing literature emphasize features that are specific to each sensory modality. In audition, for instance, the capacity to detect an interruption (or gap) in a quasicontinuous signal is well documented (Phillips \& Hall, 2002). In addition, there is a specific literature on speech (Quené, 2007) ${ }^{1}$ and music processing (Large, 2008) that contains a wealth of information on temporal resolution. In the visual perception field, one of the research issues, timeto-collision, refers to the study of the mechanisms involved in judging when an object will arrive at a given point (timeto-arrival) or will pass a given point (time-to-passage) in space (Hecht \& Savelsbergh, 2004). Indeed, regardless of modality, time and space interactions constitute a research domain unto themselves. The domain has been somewhat neglected, however, in the recent time perception literature. Although the influence of time between events influences spatial judgments (the tau effect; Henry, McAuley, \& Zaleha, 2009; Sarrazin, Giraudo, Pailhous, \& Bootsma, 2004; Sarrazin, Giraudo, \& Pittenger, 2007), it is well known that the distance between the sources marking time intervals influences the estimation of duration (the kappa effect) not only in the visual mode (see Roussel, Grondin, \& Killeen, 2009) but also in the auditory mode (Goldreich, 2007; Grondin \& Plourde, 2007a; Henry \& McAuley, 2009; B. Jones \& Huang, 1982; for a review, see ten Hoopen, Miyauchi, \& Nakajima, 2008). These space-time research avenues reflect, to some extent, a substantial amount of older literature on psychological time involving the long Piagetian tradition of the ontogenesis of temporal regulation, wherein the critical issue is the interaction of time, distance, and speed. ${ }^{2}$

Readers who are more interested in psychopathologies will also find a large number of time-related articles in the neuropsychological or psychiatric literature (see, e.g., Grondin, Pouthas, Samson, \& Roy, 2006). Distorted perception of time or problems for processing time has been reported for people suffering, for instance, from schizophrenia (Carroll, O'Donnell, Shekhar, \& Hetrick, 2009; Davalos, Kisley, \& Freedman, 2005; Davalos, Kisley, Polk, \& Ross, 2003; Davalos, Kisley, \& Ross, 2002, 2003; Elvevåg, Brown, McCormack, Vousden, \& Goldberg, 2004; Elvevåg et al., 2003; Lee et al., 2009), Parkinson's disease (J. G. Smith, Harper, Gittings, \& Abernethy, 2007;
Wearden et al., 2008), or attention-deficit/hyperactivity disorder (ADHD; Gilden \& Marusich, 2009; Toplak, Dockstader, \& Tannock, 2006). Note that timing is also used in the field of physical disorders, in which training with rhythm production is reported to help physical rehabilitation (Ford, Wagenaar, \& Newell, 2007; see Thaut, 2005).

The present review will not cover all of the aforementioned article types (social issues, consciousness, memory for the past and future, continuity of signal, space-time interaction, or pathologies in neuropsychology or psychiatry). Instead, it will focus on the literature in which normal participants are asked to provide explicit judgments about time. The term explicit is used in the present article to mark opposition with, for instance, motor activities such as those involved in speech, practicing scales on a piano, or catching a ball, in which the encoding of time is implicit (Zelaznik, Spencer, \& Ivry, 2002, 2008).

The reader is invited to consult several additional sources providing reviews or groups of articles on timing and time perception. A list of these sources is available in Table 1 in Grondin (2001b). However, many relevant books and special journal issues have been published in recent years. For people who are interested in neuroscience, there is a special issue in Brain and Cognition (Meck, 2005) and another in Cognitive Brain Research (Meck, 2004), whereas for researchers who are more interested in animal timing, there is a special issue in Learning and Motivation (Allan \& Church, 2002) and another in Behavioural Processes (Crystal, 2007). The reader will also find special issues on timing and time perception in Acta Neurobiologiae Experimentalis (Szelag \& Wittmann, 2004) and in recent issues of Philosophical Transactions of the Royal Society $B$ (Wittmann \& van Wassenhove, 2009) and NeuroQuantology (Tarlaci, 2009). In addition, there are books on different aspects of psychological time, timing, or time perception (Glicksohn \& Myslobodsky, 2006; Grondin, 2008b; Helfrich, 2003; Meck, 2003; and Strathman \& Joireman, 2005). I am not aware of all of the volumes available in foreign languages, but would like to draw attention to a book in Italian (Vicario, 2005).

\section{Main Distinctions and Empirical Issues}

Even after narrowing down the choice of research avenues to be reviewed in the present article, certain key distinctions must still be made in order to understand the literature on time perception within the context in which explicit judgments about the length of temporal intervals are required. In this section, I will present (1) the main dependent variables in time perception studies (mean and variability of time estimates), (2) the main paradigms (prospective or retrospective), and (3) the main tasks or methods; also described are (4) the need to consider the range of duration under investigation, and the particular impact on time perception of (5) attention, and of (6) emotion.

\section{Mean Estimates and Variability}

It is important to bear in mind, when examining the literature on time perception, that studies often emphasize the analysis of one or two critical dependent variables. One 
such variable is associated with the capacity to remain as close as possible to the target duration to be estimated. In other words, one quality of a timing system is to ensure that a perceived duration approximates the real duration of a stimulus. This dependent variable is emphasized when the purpose is to understand what causes distortions of perceived duration (Frassinetti, Magnani, \& Oliveri, 2009; Kanai \& Watanabe, 2006; Nakajima et al., 2004; Ono \& Kitazawa, 2010; Pariyadath \& Eagleman, 2007; for reviews, see Eagleman, 2008, ten Hoopen et al., 2008; see also Guillot \& Collet, 2005, for potential distortions when movement is mentally simulated). An example of distortion is called chronostasis - that is, the illusion that the second hand takes longer to move to its next position when someone makes voluntary saccadic eye movements while watching a silently ticking clock (Yarrow, Haggard, Heal, Brown, \& Rothwell, 2001). The same type of illusion is observed as well in the auditory (Hodinott-Hill, Thilo, Cowey, \& Walsh, 2002) and tactile (Yarrow \& Rothwell, 2003) modes. Deviation from real time is also a concern in minute range experiments that are dedicated, for instance, to the impact of playing video games on time perception (Rau, Shu-Yun, \& Chin-Chow, 2006; Tobin, Bisson, \& Grondin, 2010; Tobin \& Grondin, 2009).

Even if a timing system provides a mean perceived duration that is close to target over a series of trials, the system may be poor. It might provide a correct mean response, but the variability of information is high, with estimates being sometimes much briefer or much longer than those in real time. In other words, in many studies, it is not the mean estimates of the system that are of interest, but its capacity to minimize variability over trials (see Grondin, 2001b).

\section{General Paradigms: \\ Prospective Versus Retrospective}

In situations in which participants are asked to judge time explicitly, cognitive psychologists make a distinction between two paradigms: one in which participants are informed before they perform the task that they are required to make a time-related judgment (prospective timing), and the other in which they receive no prior warning (retrospective timing) (see Brown \& Stubbs, 1988; A. D. Eisler, H. Eisler, \& Montgomery, 2004; Hicks, Miller, \& Kinsbourne, 1976; Predebon, 1996). The present review deals primarily with prospective timing.

Retrospective timing, for its part, is mainly associated with memory processes (Block \& Zakay, 1997; Zakay \& Block, 1997, 2004), but the structure of events is a critical determinant of remembered duration (Boltz, 1992, 1994, $1995,2005)$. Note that most studies within the prospective paradigm concentrate on the processing of very brief intervals (up to a few seconds), whereas most research in the retrospective domain is generally more concerned with much longer intervals (Bisson, Tobin, \& Grondin, 2009; Grondin \& Plourde, 2007b).

\section{Specific Investigation Methods}

Many methods have been proposed for assessing mean estimates and variability, and the appropriateness of a method may well depend on the range of duration under investigation. Traditionally, authors distinguish four main methods (Bindra \& Waksberg, 1956; Wallace \& Rabin, 1960; Zakay, 1993; see Grondin, 2008a). The method called verbal estimation entails the presentation of a target interval and the requirement that a participant provide a verbal estimation of its duration, using temporal units, such as seconds or minutes. In a second method, termed reproduction, an experimenter presents a target interval with a continuous sound or flash, for instance, and a participant reproduces the length of the interval by some operation. In a third method, referred to as production, the experimenter specifies a target interval in temporal units; then, a participant produces this interval. The production usually involves two finger "taps" marking the beginning and end of the interval, or pushing a button for a duration that is judged equivalent to the target interval. ${ }^{3}$

The fourth method, called the method of comparison, is similar to those used in traditional psychophysics. Basically, a participant has to judge the relative duration of intervals presented successively and to indicate, by pressing the appropriate button, whether the second interval was shorter or longer than the first. The intervals may be marked, for instance, by continuous sounds or by continuous flashes. A participant is most often placed in a two-alternative forced choice (2AFC) condition. In psychophysics, when a standard interval is always presented first, followed by a comparison interval, the approach is known as the reminder method, and when the standard and comparison intervals vary from trial to trial, it is called the roving method (Macmillan \& Creelman, 1991). Duration discrimination is much better with the reminder method than with the roving one; in other words, discrimination is better when the standard interval, which is kept constant, is presented before a comparison interval, which is varied from trial to trial (Grondin \& McAuley, 2009; Lapid, Ulrich, \& Rammsayer, 2008; Ulrich, Nitschke, \& Rammsayer, 2006). Note that presenting intervals successively induces some bias in the perceived duration of intervals, as is the case when other sensory stimuli are under investigation. This effect is known as the time-order error - an effect already identified by Fechner, the founder of psychophysics (for reviews, see H. Eisler, A. D. Eisler, \& Hellström, 2008; Hellström, 1985).

There is a variant of the method of comparison, called the single-stimulus method. Instead of comparing directly two intervals that are presented consecutively, the participant makes a judgment after each interval presentation, and this judgment involves assigning the interval to one of two categories: short or long. There are some specific variations of this method in the animal timing literature that have been adapted for human experimentation. In a classical one known as the bisection method, the shortest and the longest intervals (anchors, or standards) of a series of intervals are first presented several times and are then followed by intervals, including the standards, that have to be categorized as being closer to one of the two anchored standards (Penney, Gibbon, \& Meck, 2008). A classical psychometric function can be drawn from these data (Grondin, 2008a): The probability of responding "long" on the $y$-axis is plotted as a function of the interval value 
on the $x$-axis. In another procedure, referred to as temporal generalization (Wearden, 1992; Wearden, Norton, Martin, \& Montford-Bebb, 2007), the central interval (a standard at midpoint) is initially presented several times, and participants should indicate (yes or no) whether subsequent intervals are of the same length as the standard.

Suppose that the interval to be compared is marked by two brief auditory signals (empty intervals) instead of by a continuous sound (a filled interval). In some conditions, a series of brief signals will mark several intervals. Participants might be assigned the task of detecting any anisochrony in the series or whether the last interval of the series is shorter or longer than the previous intervals. In such experiments, there are instances in which the second of two intervals is perceived as being much shorter than the first one- an effect known as the time-shrinking illusion (Arao, Suetomi, \& Nakajima, 2000; see ten Hoopen et al., 2008). This illusion is observed when the first interval is brief ( $<250 \mathrm{msec}$, with maximum illusion at $200 \mathrm{msec}$ ), and when the difference between the second and the first interval is more than $0 \mathrm{msec}$ and less than $100 \mathrm{msec}$ (with a maximum illusion at $80 \mathrm{msec}$ ). Participants might also be asked to compare the relative length of intervals in two consecutive series of intervals. In most studies using this method, intervals last between $250 \mathrm{msec}$ and $1 \mathrm{sec}$. With this method, it has been shown that using multiple- instead of single-interval presentations improves discrimination (Drake \& Botte, 1993), and that this improvement depends not only on the number of intervals in the first sequence (usually standard), but also on the number of intervals in the second (comparison intervals) sequence (McAuley \& Miller, 2007; Miller \& McAuley, 2005). Indeed, depending on the modality of stimuli marking sequences, it looks as if increasing the number of comparison intervals, regardless of whether they are presented first or second, is the key factor affecting discrimination (Grondin \& McAuley, 2009). Note that participants are very sensitive not only to the immediate intervals that are presented (local effect), but also to the series of intervals presented within a block of trials (M. R. Jones \& McAuley, 2005; see Barnes \& Jones, 2000, or McAuley \& Jones, 2003, for the notion of expectancy profile). Figure 1 offers a schematic view of the methods reviewed previously.

\section{Critical Times}

Assessing the literature on time perception also inevitably requires keeping in mind what range of duration is under investigation. The human organism comprises multiple levels of cyclic activities or sorts of temporal rates, extending from very large scales (e.g., menstrual cycles, circadian rhythm) to much shorter ones (e.g., the firing rate of cortical cells) (see Buonomano, 2007; Mauk \& Buonomano, 2004; Wackermann, 2007). In fact, a human observer has the impression that physical time is a continuous flow that can be divided indefinitely into smaller units. But whatever physical time is (Buccheri et al., 2003; Lobo, 2008), experimental psychologists have been tempted to identify a variety of phenomena on a temporal continuum that reflect fundamental transitions about the way the brain captures information.
The field of time perception has been more concerned with intervals in the range of $100 \mathrm{msec}$ to a few seconds; intervals up to a minute or so are common in the animal timing literature. Intervals below a second in the human timing literature have received a great deal of emphasis, probably because they are related to fundamental adaptive behavior, such as speech processing, motor coordination, and music perception. The 0.1 - to 1 -sec range has received quite a bit of attention because it covers (1) the debatable notion of indifference interval (around $700 \mathrm{msec})^{4}$ - that is, an interval in which there would be no tendency to overestimate or underestimate durations (see H. Eisler et al., 2008); (2) the highest sensitivity for tempo discrimination, located somewhere in the range of 300 to $800 \mathrm{msec}$ (Drake \& Botte, 1993), or maybe more specifically at $500 \mathrm{msec}$ (Friberg \& Sundberg, 1995) or $600 \mathrm{msec}$ (Fraisse, 1957); and (3) the preferred tapping tempo (i.e., the spontaneous preferred rate in a tapping task), which is approximately $350 \mathrm{msec}$ for children, $600 \mathrm{msec}$ for young adults, and $700 \mathrm{msec}$ for seniors (McAuley, Jones, Holub, Johnston, \& Miller, 2006; see also Zelaznik, Spencer, \& Doffin, 2000).

Many researchers in the field of time perceptionmainly those adopting a neuroscientific perspective (see below) - have emphasized a distinction between intervals above and below $1 \mathrm{sec}$ (Penney \& Vaitilingam, 2008). This distinction is based on differential pharmacological effects (Rammsayer, 2008) and on the fact that the processing of smaller intervals is sensory based, or benefits from some automatic processing, whereas the processing of longer intervals requires the support of cognitive resources (Hellström \& Rammsayer, 2004; Lewis \& Miall, 2003b; Rammsayer \& Lima, 1991; but see Rammsayer \& Ulrich, 2005). This is somewhat reminiscent of Fraisse's (1984) distinction between time perception and time estimation. This 1-sec transition period remains somewhat arbitrary. ${ }^{5}$ However, there is certainly some turning point on the time continuum in which an observer would benefit from adopting a segmentation strategy. The aim of a segmentation strategy is to divide a given interval into smaller and usually equal portions. In duration discrimination, benefits can be expected from counting numbers explicitly when intervals are longer than $1.2 \mathrm{sec}$ (Grondin, Meilleur-Wells, \& Lachance, 1999). When examining the human timing literature, the reader should consider whether participants were asked to segment temporal information or to refrain from using any strategies such as foot tapping, imaging, repetitive movements, or counting seconds (Grondin \& Killeen, 2009; Grondin, Ouellet, \& Roussel, 2004; Hinton \& Rao, 2004). Indeed, there are several reports that show that at certain points between 1 and $2 \mathrm{sec}$, the Weber fraction 6 is not constant; that is, it is higher at 1.5 and $2 \mathrm{sec}$ than at $1 \mathrm{sec}$ (Drake \& Botte, 1993; Grondin, 2001a; Lavoie \& Grondin, 2004; Madison, 2001). The fact that the Weber fraction does not remain constant for a larger range of durations could be argued to reflect short-term memory limitations (Gilden \& Marusich, 2009; Grondin, 2001c).

Finally, readers who approach the time perception literature from a temporal continuum perspective will also encounter the concept of psychological present (or spe- 


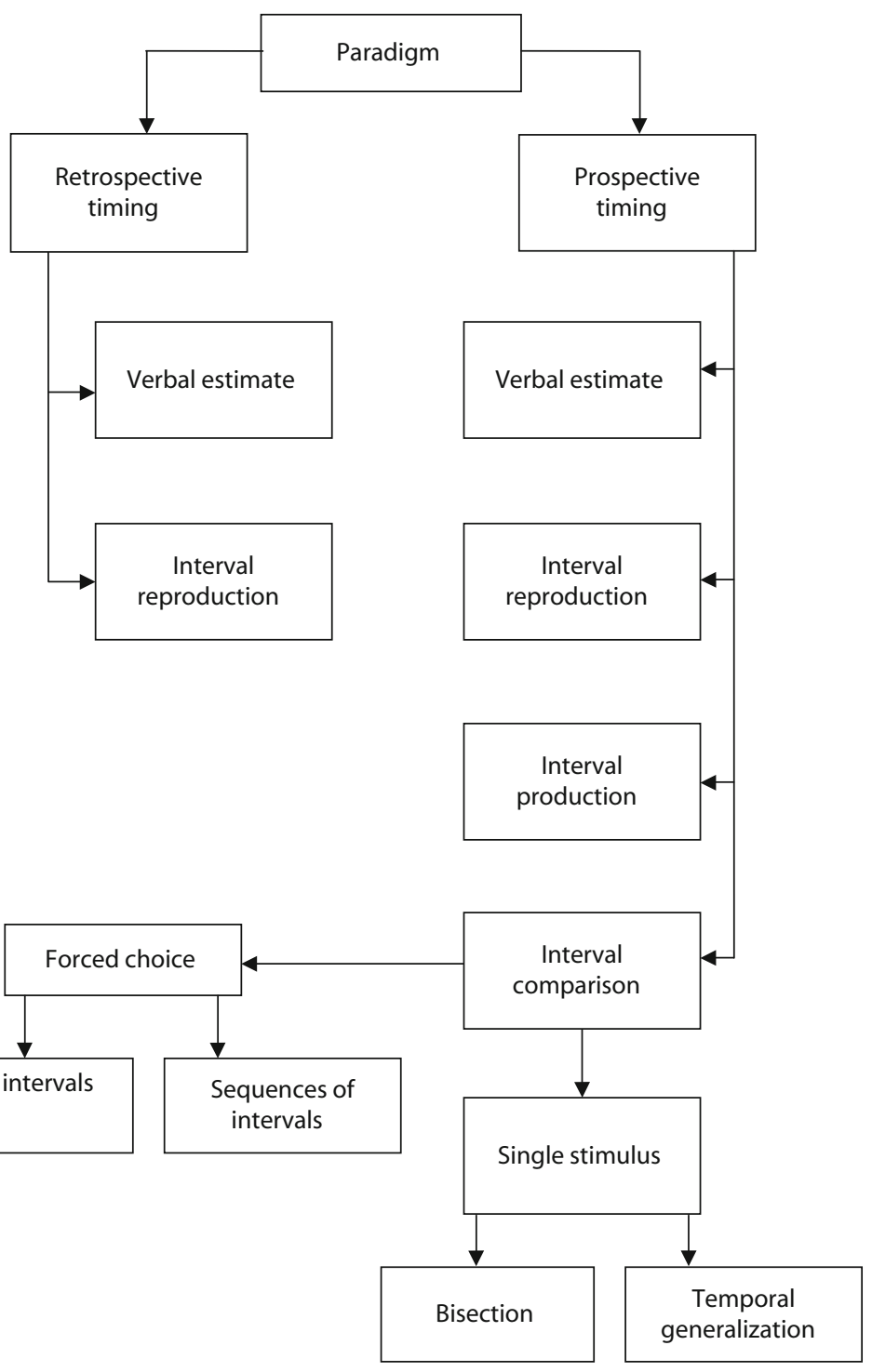

Figure 1. Schematic of the main methods used in the study of timing and time perception.

cious present in James, 1890). This concept was defined by Fraisse (1978) as "the temporal extent of stimulations that can be perceived at one given time, without the intervention of rehearsal during or after the stimulation" (p. 205), and it would range from 2 to $5 \mathrm{sec}$. Somewhat along the same lines, Pöppel $(1997,2004)$ argued, on the basis of converging evidence from different fields, that the neurocognitive machinery is based on a 3-sec temporal window that provides some sense of nowness.

\section{Attention}

The involvement of attention mechanisms is a fundamental issue in contemporary research on timing and time perception (Brown \& Boltz, 2002; Buhusi \& Meck, 2009; Burle \& Casini, 2001; Hemmes, Brown, \& Kladopoulos, 2004). Although the variability of estimates is sometimes argued to depend on attention, the role of attention is most commonly used for explaining the perceived duration of intervals (Glicksohn, 2001; P. U. Tse, Intriligator, Rivest, \& Cavanagh, 2004). Essentially, the literature on prospective timing reveals that attending to the flow of time increases perceived duration and, somewhat similarly, that being distracted from time results in the shortening of perceived time.

As we will see in another section, attention is a key concept in many models of time perception or estimation, including the more purely cognitive ones in which no reference is made to a central timekeeping device (Block, 2003), and M. R. Jones and Boltz's (1989) dynamic attending approach, which is based on environmental cues. The pacemaker-counter models, which will be described later in the present review, also acknowledge the critical role of attention at different stages of the timing process (switch errors). In the few studies briefly described in the present article, attention is viewed as a causal agent of perceived duration. The selected studies should reflect some 
versions of a fundamental perspective in the attention literature, that of limited processing capacity due to limited available resources. The reader is invited to consult Brown (2008) for an extensive review of the range of effects of attention on time perception in relation to the most classical issues of the attention literature.

A central idea in research on time perception that is based on the notion that there is a limited pool of attentional resources is that more attention to a nontemporal task reduces attention to time in dual-task conditions. It has been shown, for instance, that the presence of a concurrent task during a timing task decreases the accuracy of time estimations when compared with a single-task (temporal) condition (Brown, 2006, 2008; Brown \& Merchant, 2007; Field \& Groeger, 2004; Zakay, 1998); however, attempts to determine the extent to which increasing the difficulty of the nontemporal task results in more interference on timing show a less clear pattern of results (see Brown, 1997, 2008; see Figure 2). Nonetheless, according to Brown (2008), the interference caused by competing tasks on timing is "the most well-replicated finding in all the time perception literature" (p. 119).

Some of the evidence showing the critical role of attention in time perception comes from a strategy in which a participant is asked before each trial to share a specific proportion of attention between two separate tasks - a temporal and a nontemporal one - that is, to discriminate the length (temporal) and the intensity (nontemporal) of a sound or of a visual signal. This proportion is the independent variable - for instance, duration only, maximum duration/minimum intensity, half/half, maximum intensity/minimum duration, and intensity only (Casini \& Macar, 1997; Grondin \& Macar, 1992; Macar, Grondin, \& Casini, 1994). Focusing more attention on time results in fewer discrimination errors and longer perceived duration (Macar et al., 1994). The influence of attentional resources on time perception has also been demonstrated with multiple timing strategies involving, for instance, a series of partially overlapping visual displays marking intervals of different lengths that had to be timed for eventual reproduction. It has been shown that the variability and deviation from target increase with the number of events to be timed (Brown, Stubbs, \& West, 1992; Brown \& West, 1990). In other words, increasing attentional demand has a direct influence on time reproduction.

Other evidence that allocating attention influences perceived duration comes from studies in which an interruption in a signal to be timed is expected (Fortin et al., 2009). Note that "expecting" here should not be confused with the key concept of expectancy in M. R. Jones and Boltz's (1989) dynamic attending approach, in which environmental cues lead attentional energy toward specific points in time. In Fortin et al.'s (2009) study, the participant is anticipating the occurrence of a break, and it is the location of the break (the moment of occurrence) that is manipulated. So, if a participant has to reproduce the duration of a sound that is interrupted by a break, the location of the break will influence the length of the reproduced interval. More specifically, the longer the participant is expecting a break (i.e., the longer the sound in the prebreak portion), the more attention will be allocated to the arrival of the break, which results in less attention to time and in shorter interval reproduction (see, e.g., Fortin, Bédard, \& Champagne, 2005). Additionally, manipulating the period before presenting a brief time interval to be discriminated affects the perceived duration of the interval: Increasing the foreperiod increases the likelihood that the interval will be presented. This expectation prepares attention to time. Consequently, longer foreperiods result in longer perceived intervals (Grondin \& Rammsayer, 2003).

\section{Emotions}

Although there is abundant literature on the effect of attention on time perception, there is a relatively new and rapidly flourishing avenue of research on the impact of

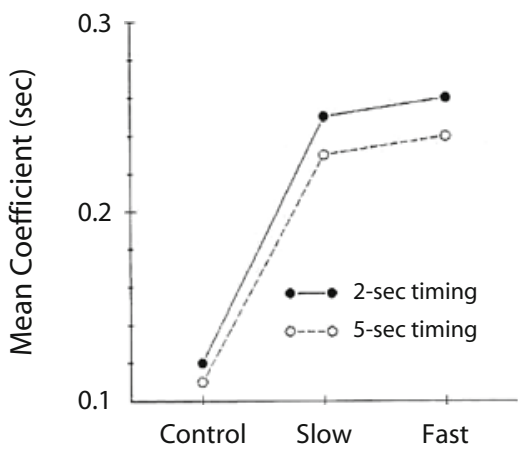

Tracking Condition

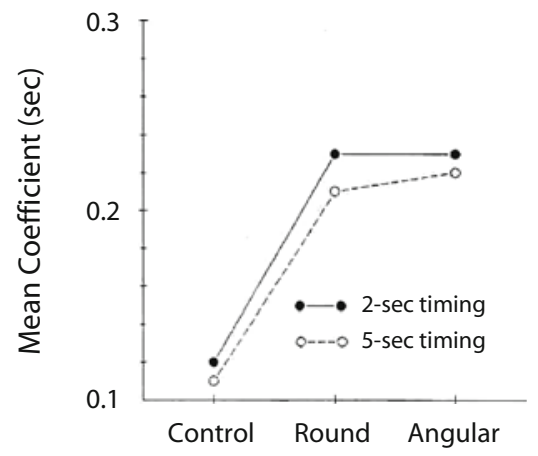

Distractor Condition

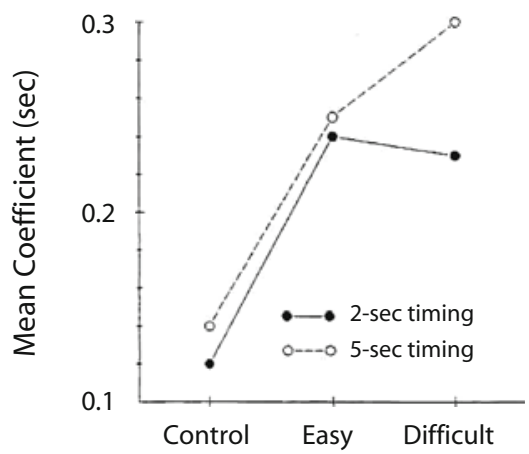

Math Condition

Figure 2. Results from Brown (1997) showing the effect of dual tasks on interval production (see note 3). The dependent variable on the $y$-axis is the coefficient of variation (the variability of productions to mean productions ratio), with the higher scores indicating more variability (lower performances). The target intervals to produce were either 2 or 5 sec. The results were obtained with a motor (tracking, left panel), a visual (search with distractor, middle panel), and a cognitive (mental arithmetic, right panel) nontemporal secondary task. From "Attentional Resources in Timing: Interference Effects in Concurrent Temporal and Nontemporal Working Memory Tasks," by S. W. Brown, 1997, Perception \& Psychophysics, 59, pp. 1124, 1127, and 1130. Copyright 1997 by the Psychonomic Society. Adapted with permission. 
emotion on time judgments - primarily, perceived duration. There is modest literature on the effect of emotion on retrospective judgments of intervals of a few minutes (Bisson et al., 2009; Glicksohn \& Cohen, 2000; Hornik, 1992; Kellaris \& Kent, 1992). Closer to the focus of the present review are the recent findings with prospective paradigms and intervals in the range of seconds.

For instance, a bisection task involving intervals lasting $0.4-1.6 \mathrm{sec}$ showed that intervals are perceived as longer when angry faces are presented during the intervals as compared with when neutral faces are shown (DroitVolet, Brunot, \& Niedenthal, 2004). This effect applies to perceived duration, but not to the level of variability. Droit-Volet et al. (2004) reported that the distortion effect also applies to the presentation of fearful, happy, and sad faces, but to lesser degrees (cited in Droit-Volet \& Meck, 2007). Gil, Niedenthal, and Droit-Volet (2007) also reported, with a temporal bisection task (0.4 to $2.4 \mathrm{sec})$ involving children as participants, that presenting angry faces leads to longer perceived duration than does presenting neutral faces (see also Effron, Niedenthal, Gil, \& Droit-Volet, 2006). Finally, presenting faces representing older persons leads to shorter perceived duration than does presenting faces of younger persons (Chambon, Gil, Niedenthal, \& Droit-Volet, 2005).

There are reasons to believe that the influence of affective valence (positive or negative) on time perception depends on the level of arousal. Angrilli, Cherubini, Pavese, and Mantredini (1997) showed that, for intervals lasting 2-6 sec, negative valence leads to longer perceived duration than does positive valence under high arousal conditions; however, the reverse is observed under low arousal conditions. Indeed, it is possible that the arousal generated by emotion accelerates the mechanism (the internal clock - pacemaker - described below) that is responsible for judging time, which results in longer perceived duration (for a review, see Droit-Volet \& Gil, 2009).

\section{Summary}

When studying the time perception literature, the reader is invited to keep in mind, for instance, whether an article is dealing mainly with perceived duration and the factors affecting it, with the variability of a series of estimates, with prospective or retrospective timing, or with a specific range of duration. Traditionally, the main methods of investigation are verbal estimates, interval production, interval reproduction, and interval comparison. The latter case includes the categorization of intervals as being short or long, or the discrimination of two or more successive intervals. Finally, there is a huge amount of empirical work on the role of attention in time perception, whereas research linking emotions and time perception is less abundant, despite recent advances, and concerned mainly with perceived duration.

\section{Mechanisms and Models}

Essentially, one can distinguish two ways of theoretically approaching the question of the processing of tem- poral information, depending on whether timing is seen as the output of a dedicated system.

\section{No Central Clock}

Many authors-usually those who are interested in human motor timing, animal learning, or human cognition - have argued that there is no need to refer to a clock for describing timing behaviors (Block, 1990; Hopson, 2003; Zeiler, 1998, 1999). Indeed, myriad theoretical explanations make no mention of a central mechanism that is dedicated to the processing of temporal information. For instance, researchers with a cognitive background have described time perception in terms of cognitive mechanisms, without referring to the idea that there is an internal clock (see Block, 2003; Block \& Zakay, 2008). These researchers have provided explanations in terms of attentional or memory mechanisms and are often interested in long intervals (Ornstein, 1969). In addition, in the specific field of human motor control, a distinction is made between event timing and emergent timing (see Zelaznik et al., 2008). Although the first suggests the need for an explicit representation of time, the latter does not. From a dynamical systems view, temporal regularities in movements emerge from the control of movement dynamics. This distinction received support when it was shown that the timing variability in a tapping task is not linked to that observed in a continuous circle-drawing task (Robertson et al., 1999; see also Spencer \& Zelaznik, 2003; Zelaznik et al., 2002). In brief, from an event-versusemergent-timing perspective, it is argued that a singletiming process (or central clock) cannot account for the panoply of temporal regularities observed in the various motor-timing tasks.

A recent class of theoretical explanations about timing judgments could be referred to as intrinsic models (Ivry \& Schlerf, 2008), or as being dependent specifically on a modality or a coordination-dependent system (Jantzen, Steinberg, \& Kelso, 2005). A most representative example of this no-dedicated-system view is the one referred to as a state-dependent network (Buonomano, 2007; Karmarkar \& Buonomano, 2007). In this case, timing does not depend on a clock, but on time-dependent changes in the state of neural networks. Durations are represented as spatial patterns of activity, and judging duration means being able to recognize these patterns.

Recent findings in the field of visual perception have led to the development of a modality-specific perspective. When a flickering stimulus is presented in a specific region of visual space and leads to local adaptation, there is a reduction of the perceived duration of subsequent stimuli if they are presented in the same specific region, but not if they are presented in other regions of visual space (Johnston, Arnold, \& Nishida, 2006). Burr, Tozzi, and Morrone (2007) also reported that the timing of visual events is spatially selective. Along the same lines, Morrone, Ross, and Burr (2005) showed that saccadic eye movements affect the perceived duration of visual events but not of auditory events. This group of findings supports the idea that estimating the duration of visual signals could be embed- 
ded within the visual modality. There would be spatially localized visual-neural mechanisms.

Such a modality-specific perspective provides a potential explanation as to why there are so many differences between sensory modalities when time intervals are to be discriminated or categorized (Grondin, 1993; Grondin, Roussel, Gamache, Roy, \& Ouellet, 2005). Although it is known that auditory intervals are perceived as longer than visual signals of the same duration (Goldstone \& Lhamon, 1974; Lhamon \& Goldstone, 1974; Walker \& Scott, 1981; Wearden, Edwards, Fakhri, \& Percival, 1998), it is also known that sensitivity to time is much higher (lower threshold, or less variability) when intervals are marked by auditory rather than by visual signals (for a review, see Grondin, 2003). Moreover, this superiority of the auditory over the visual mode for temporal processing is also observed when sequences of sounds or flashes are used (Grondin \& McAuley, 2009; see the Appendix). In particular, when empty intervals are marked by two brief sensory signals that are delivered from different sensory modalities, sensitivity to time is much lower than it is when intervals are marked by signals from only one modality, either auditory or visual (Grondin \& Rousseau, 1991; Grondin et al., 2005). Finally, the modality-specific perspective would also account for the difficulty of transferring temporal learning from the auditory to the visual modality (Grondin, Bisson, Gagnon, Gamache, \& Matteau, 2009; Grondin, Gamache, Tobin, Bisson, \& Hawke, 2008; Lapid, Ulrich, \& Rammsayer, 2009).

\section{Central or Dedicated Device: The Internal Clock}

A much longer tradition of thinking in the field of time perception involves the presence of a central mechanism that is responsible for estimating time. For the sake of simplicity, this section on theoretical issues is organized according to two main perspectives: the pacemaker-counter process versus the oscillator process. In the latter case, temporal control is usually reported to be based on a dynamic, nonlinear system (Large, 2008; Schöner, 2002), in contrast with the linear perspective of a pacemakercounter device that is most often embedded within an information-processing perspective (Ivry \& Richardson, 2002; Rosenbaum, 2002; Wing, 2002).

Note that there are other theoretical propositions, or types of timers, for explaining the ability to keep track of time. For instance, Staddon and Higa $(1996,1999)$ did not refer to any type of pacemaker or oscillator for explaining timing. Instead, they assumed that there was a cascade of interval timers, with specific amounts of memory-strength decay determining specific time periods. Wackermann and Ehm (2006) provided another example of a pacemaker- or oscillator-free model by positing that time is accumulated by inflow/outflow systems (known as the dual-klepsydra model). Such a model applies well to reproduction tasks (see also H. Eisler, 1975; H. Eisler et al., 2008).

Oscillators, expectation, and entrainment. Oscillator models could be especially useful with a given type of temporal resolution - that is, when there are temporal intervals embedded in sequences of signals. Indeed, there are occurrences of physical regularities within the flow of events in the environment (take, for instance, music, speech, or even locomotion or interlimb coordination; see M. R. Jones, 1976; M. R. Jones \& Boltz, 1989). These regularities mark coherent beginnings and ends for several succeeding time spans. This temporal regularity makes forthcoming events predictable and sets (within an observer) an attending attitude, which M. R. Jones and Boltz called, within their dynamic attending theory (DAT), a future-oriented attending mode. With this view, the accuracy of temporal judgments depends on the temporal coherence of events and on the capacity to synchronize the internal rhythmicity of attending, or attunement, with the appropriate external level of rhythm that the environment offers.

M. R. Jones and Boltz's (1989) DAT can be interpreted in terms of an oscillatory process made of two components: a nonlinear oscillator and an attentional energy pulse rhythm (for a formal description, see Large \& Jones, 1999). The summation of these components provides an attentional rhythm. The period (the time span between the peaks of a given cycle) and phase (the difference between the onset of the stimulus and the peak of an attentional pulse) of this internal oscillator adapt according to the temporal structure of environmental stimuli (see also Barnes \& Jones, 2000; Large, 2008; McAuley \& Jones, 2003). The internal oscillator changes gradually and adapts to allow the attentional rhythm to get closer to the stimuli onset.

In brief, the consequence of this oscillator adaptation to the context (i.e., to a series of isochronous stimuli) is the synchronization of attentional pulses and stimuli onsets and, eventually, of the narrowing of these pulses. This model is referred to as the entrainment model. Entrainment underlines a key feature of the process: The oscillator continues to adapt, if the context permits, until the attentional peaks are well aligned with the expected stimulus onsets.

This entrainment model is an interesting case of the oscillator approach because it accounts for a large category of temporal phenomena - namely, those cases in which there are regularities available in the environment and a possibility to expect the moment of arrival of an event. However, there are other oscillator models that are not specifically concerned with expectations. For instance, the model proposed by Church and Broadbent (1990) emphasizes the role of an oscillator process, with specific combinations of periodic neural events for providing a representation of time. In this model, Church and Broadbent assumed the presence of multiple oscillators offering many periodicities covering very large time scales. The 11 proposed oscillators have mean periods of 0.2 to $204.6 \mathrm{sec}$.

Another interpretation based on the oscillatory process was offered by Treisman, Faulkner, Naish, and Brogan (1990). They described the internal clock as a system made of two components linked in sequence. One of the components is a temporal oscillator (TO), and the other, a calibration unit (CU). The role of the TO in this model remains that of a pacemaker. The TO emits pulses that are transmitted to the $\mathrm{CU}$, whose role is to control the pulse rate that multiplies the initial frequency by a calibration factor.

Pacemaker-counter models. In a dominant view in the field of time perception, temporal judgments 
are assumed to be based on a single internal clock, described as a pacemaker-counter device (Creelman, 1962; Rammsayer \& Ulrich, 2001; Treisman, 1963). Such a pacemaker-counter device forms the basis of many theoretical propositions. This view can be summarized as follows. The pacemaker emits pulses that are accumulated in a counter, and the number of pulses counted determines the perceived length of an interval. The reason why one makes errors in judging time depends on several factors. Older studies have focused primarily on the properties of the pacemaker, but there are other sources of variance. Indeed, 35 years ago, Allan and Kristofferson (1974) pointed out in an article on time perception that

the input process is thought of as one which takes a measure of the temporal extent of a stimulus pattern, compares the measure either to an internal standard or to the memory of a measure of a standard stimulus, and triggers a response, which may or may not be biased, depending on the outcome of the comparison process. (p. 26)

They underlined the critical role of the three levels of processes emphasized in the information processing version of what is probably the most frequently cited contemporary model derived from the pacemaker-accumulator perspective: the scalar expectancy theory (SET; Gibbon, 1977, 1991, 1992; Wearden, 2003). These levels are the clock (the input process), memory, and decision making (see Meck, 2003).

SET is characterized by two fundamental properties. The first, the mean representation of time for a series of temporal judgments, equals real time. In terms of classical psychophysics, the property conforms to psychophysical law when the relation is linear (exponent $=1$, but see H. Eisler, 1975, 1976, 2003; H. Eisler et al., 2008; see
Figure 3). The second property, the variability (often expressed as one standard deviation, $\sigma$ ) of time judgments, increases linearly with the mean representation of time (Lewis \& Miall, 2009). Hence, if the proportion between variability and the mean is constant, it is said to be scalar, which is essentially a form of Weber's law (Killeen \& Weiss, 1987). However, this property is more precise than in the case of the Weber law. For example, when psychometric functions that are issued from a bisection procedure are normalized by their mean, they superimpose (see Church, 2003; Wearden \& Lejeune, 2008).

Pacemaker error. The reliability of the pacemakerthat is, the properties of pulse emission - is often reported to be a main cause of timing error. The mode of pulse distribution is assumed to be either deterministic (regular interpulse intervals) or stochastic (random interpulse intervals). For instance, in early time-perception models, Creelman (1962) proposed a counting model with a pacemaker emitting pulses according to a stochastic distribution mode (a Poisson process) with a fixed frequency, whereas Treisman's (1963) model involved a deterministic pacemaker with a variable frequency that was related to arousal.

Counter error. As compared with the pacemaker case, a more limited number of models have emphasized the fallibility of the counter (Killeen \& Fetterman, 1988), although Killeen and Taylor (2000) proposed a model involving a cascade of counter systems. If counting is hierarchical, as it is when decimal or binary systems are used, the magnitude of the timing error increases disproportionately each time the next stage in the counter must be set. For decimal counters, for instance, this occurs at $10 \mathrm{~s}, 100 \mathrm{~s}$, and so on. Dropped counts can become increasingly costly when larger numbers are counted. Consequently, the mean count registered should grow approximately as a power function of the target number: $\mathrm{C}=\mathrm{N}^{\alpha}$, where $\alpha=\log (\mathrm{B}) /$
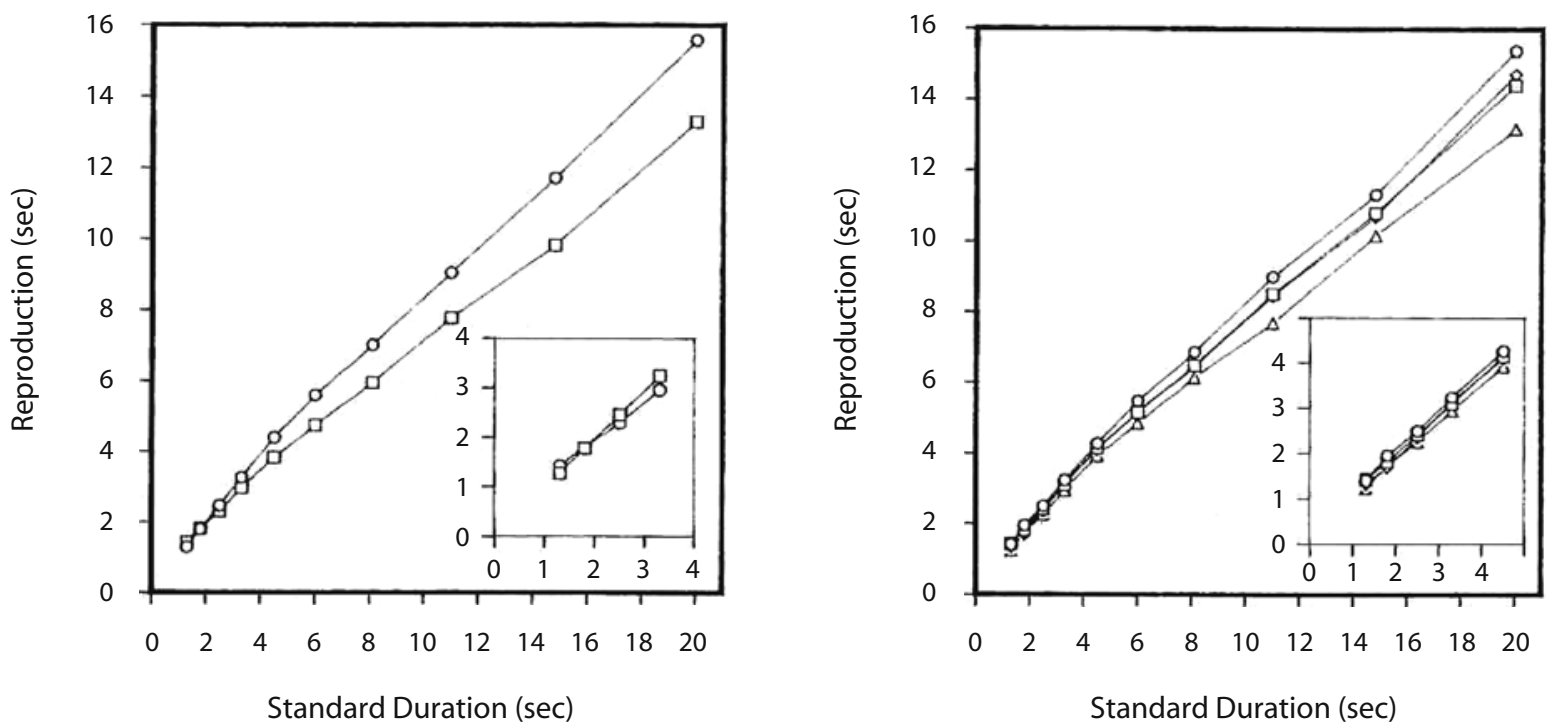

Figure 3. Mean interval reproductions as a function of physical time. Left panel: Results for females (circles) and males (squares). Right panel: Results as a function of auditory intensity at 10 (circles), 25 (diamonds), 40 (squares), and 55 (triangles) dB SPL. From “Time Perception: Effects of Sex and Sound Intensity on Scales of Subjective Duration,” by H. Eisler \& A. D. Eisler, 1992, Scandinavian Journal of Psychology, 33, p. 344. Copyright 1992 by Wiley-Blackwell. Adapted with permission. 
$\log (\mathrm{B} p), \mathrm{B}$ being the base of the counter system used, and $p$ the probability that the input will correctly increment each stage of the counter (Killeen \& Taylor, 2000).

Switch and marking error. The switch is the part of the clock process that is directly associated with the mechanisms of attention (Meck, 1984). When the switch is closed, the pulses that are emitted by the pacemaker are accumulated in the counter. Indeed, it is the amount of attention paid to time that determines the accumulation of pulses in the counter. In a dual-task manipulation of the type described earlier, where in some conditions participants may have to judge both the intensity and the duration of a signal (Macar et al., 1994) when full attention is dedicated to time, the switch is closed and the accumulation is at its maximum. More attention leads to longer perceived duration and to fewer interval discrimination errors. Note that some authors also refer to the existence of a gate that determines the flow of pulses when attending to time, the switch being associated with attending to a duration-onset signal (see, e.g., Block \& Zakay, 2008). Indeed, a part of the variance observed in a timing task is due to the variability caused by the latency, at both the onset and offset stages, between the physical and internal signals marking the interval to be judged. These marking errors would explain some of the sensory or structural effects on duration discrimination (Grondin, 1993, 2003; see also Bendixen, Grimm, \& Schroger, 2006; Mitsudo et al., 2009; C.-Y. Tse \& Penney, 2006). Moreover, some authors have even claimed that all of the variability in the timing process is caused by these latencies (Allan, Kristofferson, \& Wiens, 1971).

Memory and decision processes. Even within the scope of a pacemaker-counter perspective, it is not possible to neglect the part of variance in a timing task belonging to memory and, to some extent, to decisional processes (Gibbon, Church, \& Meck, 1984). In a bisection task, transferring into memory the accumulation of a given interval would involve a multiplicative storage constant, $K^{*}$, whose variability is normally distributed (L. A. Jones \& Wearden, 2003). Variance in such a task may also be associated with the distribution in reference memory of each of the short (S) and the long (L) intervals to be learned (Penney, Gibbon, \& Meck, 2000). In that case, judging a given interval would depend on the similarity between this interval and the central value of the distribution for S and L. Allan and Gerhardt (2001) have argued that S and L combine and form a single value $(\mathrm{m})$; when the interval to be judged (a) exceeds that in memory, the interval is judged as being long. The decision-making rule that applies to this case remains debatable, but one possible candidate is the ratio rule $(m-a / m)$ (see, e.g., Church, 1997; Killeen, Fetterman, \& Bizo, 1997; Wearden, 2004).

Some recent research on temporal memory was based on interval categorization (temporal generalization or bisection tasks), in which a series of intervals was assigned to one of two categories: short or long. In some conditions, there were blocks of trials in which intervals were marked by either auditory or visual signals. This research shows that intervals marked by different sensory modalities use a common memory representation (see, e.g., Grondin,
2005 , for intervals $<1 \mathrm{sec}$; Penney et al., 2000, for intervals lasting $3-6 \mathrm{sec}$ ), and that the influence of one interval type on the other lasts at least a few minutes (Gamache \& Grondin, 2008). Moreover, some studies also employed simultaneous timing - that is, blocks of trials in which intervals from different duration ranges were used (intervals around $250 \mathrm{msec}$ [from 200 to $300 \mathrm{msec}$ ] and around $750 \mathrm{msec}$ [from 600 to $900 \mathrm{msec}$ ] in Grondin, 2005; see Figure 4). The results show that participants used different memory representations for each duration range, with the possibility of some interference when the intervals are too close (Grondin, 2005; Klapproth, 2009; L. A. Jones \& Wearden, 2004; Ogden, Wearden, \& Jones, 2008).

\section{Summary and a Comment}

When approaching the time-perception literature, the reader will find different theoretical perspectives. Some researchers will not adopt an internal-clock perspective, such as researchers who study motor control and who adopt a dynamical systems perspective, and visual perception researchers, who claim that time perception is an emergent property within the visual modality. However, many timeperception researchers do adopt an internal-clock perspective, based on either oscillatory processes (such as DAT) or on a pacemaker-counter device (such as SET).

DAT is better equipped than SET to address how people use event time structure in ordinary environments to attend to aspects of real-world events, such as speech, music, birdsong, and so on, but it does not do well with single, isolated intervals - that is, when there is no basis for picking up information about a context rate or rhythm. DAT needs to tune into a whole sequence of trials. SET is designed to address how people use/remember a discrete (standard) time interval in laboratory tasks in which participants must judge a single, isolated comparison time interval later on. With a rhythmic context sequence containing missing beats, for instance, prior to a to-be-judged time interval, SET breaks down, whereas the oscillator perspective of DAT does not (McAuley \& Jones, 2003). Finally, unlike DAT, SET cannot predict whether people will be more accurate in identifying nontemporal (e.g., tone pitch) properties of temporally expected items rather than of temporally unexpected items (M. R. Jones, Johnston, \& Puente, 2006).

\section{A Neuroscientific Approach}

In a perspective in which it is assumed that there is a specialized brain system for representing temporal information, one is justified in searching for the structures involved in this system. Indeed, the emergence of many new techniques has produced a large body of neuroscientific studies of temporal processing over the past 15 years, which has resulted in increasing evidence that specific structures in the human brain play a role in the processing of temporal information (Coull, Vidal, Nazarian, \& Macar, 2004). Since it is not possible to provide a complete review of the neuroscientific literature on timing and time perception, only the main brain structures and issues involved in explicit judgments of time will be reviewed in the present article. ${ }^{7}$ 


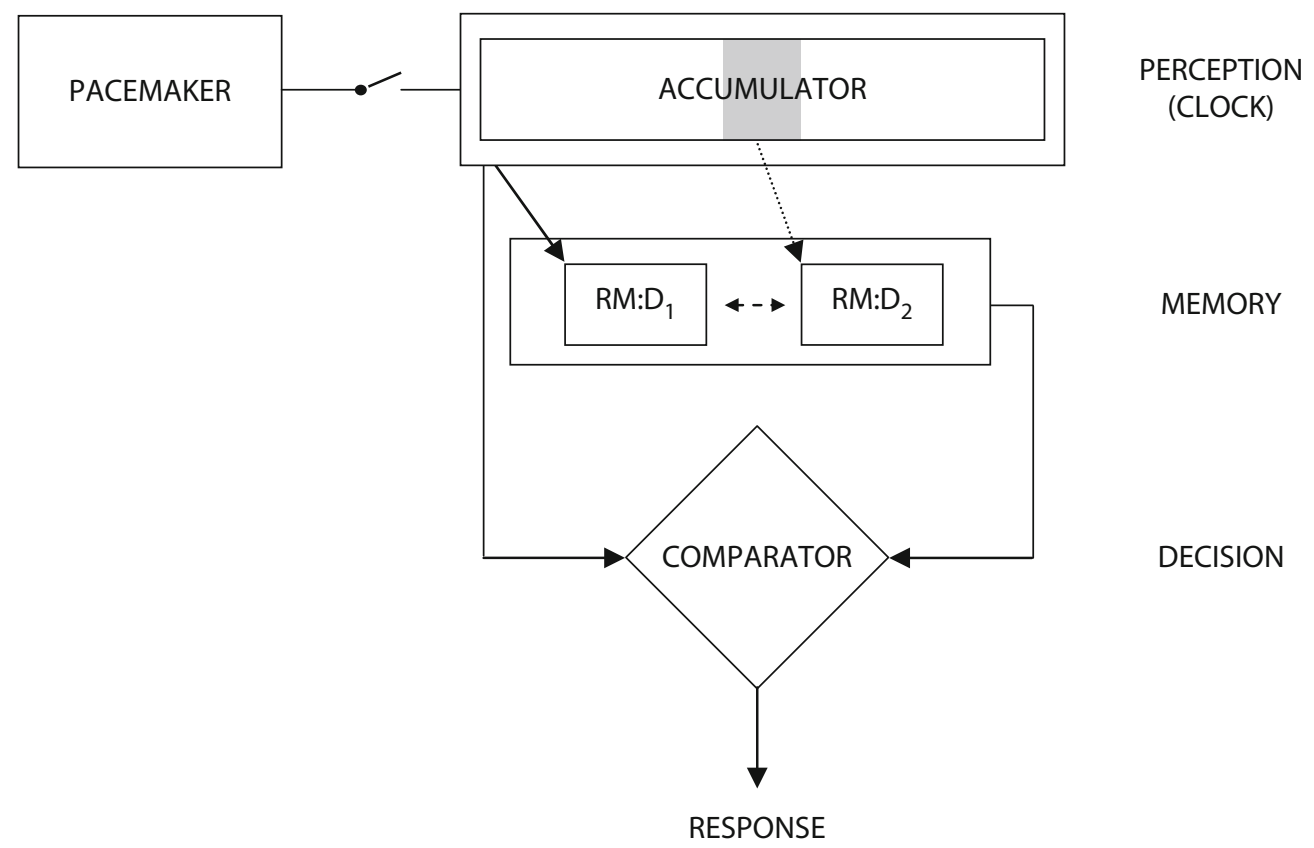

Figure 4. Schematic of the information-processing version of the scalar expectancy theory adapted to a simultaneous timing condition. At the perceptual level, or clock level, there is a pacemaker-accumulator (or counter) device, with a switch component between the two. The diagonal arrows indicate that, once a level of accumulation is reached, it is with another internal representation in reference memory (RM) that the interval for a given trial will be compared. The accumulation level that has to be reached may vary from trial to trial (gray zones in the accumulator). The bidirectional arrow between RM components indicates that the internal representations may exert mutual influence. $D_{1}, D_{2}$, Distribution 1 or 2 , associated with a given level of accumulation of pulses. From "Overloading Temporal Memory," by S. Grondin, 2005, Journal of Experimental Psychology: Human Perception and Performance, 31, p. 876. Copyright 2005 by the American Psychological Association. Reprinted with permission.

For a more comprehensive review of time-perception data obtained with imaging techniques, the reader is invited to consult Penney and Vaitilingam (2008), who provided a series of precise summary tables (see also Macar et al., 2002). Those who are most interested in EEG should read Macar and Vidal (2009). Readers will also find a good summary of results on the neural correlates of time perception in Rubia (2006), which includes imaging data associated with time management, as well as a nice review of brain-based models of timing in Buhusi and Meck (2005).

In the present brief review, the roles of the cerebellum, of different cortical areas, and of subcortical structures (basal ganglia) will be summarized. Evidence is drawn mainly from EEG, fMRI, and repeated transcranial magnetic stimulation (rTMS). Although fMRI is known for providing excellent spatial resolution, EEG is a particularly fine tool for investigating the mechanisms involved in time perception, since its temporal resolution is superior to that of fMRI.

\section{Cerebellum}

More than 40 years ago, the idea of the involvement of the cerebellum in the biological bases of temporal processing was already a serious hypothesis (Braitenberg, 1967), but it is mostly in the past 20 years that the potential role of the cerebellum has been emphasized. This work is em- bedded within a more general hypothesis, or framework, in which it is argued that performance in time perception and time production tasks should be correlated. And there is evidence that they are (Ivry \& Hazeltine, 1995; Keele, Pokorny, Corcos, \& Ivry, 1985; McAuley et al., 2006). Therefore, if the perception and production of timing reflect a common process, they should be controlled by the same brain regions. Keele and Ivry (1991) and Ivry, Keele, and Diener (1988), who worked with humans, showed that lateral cerebellar lesions increase the variability of intervals produced with a series of taps. Although cerebellar patients had more difficulty than did control participants in discriminating brief intervals marked with sounds, these two groups were equally efficient in discriminating the intensity of sounds (Ivry \& Keele, 1989). Therefore, the deficit observed for processing time is not due to a general auditory processing incapacity. Indeed, the cerebellum is argued to be involved in a variety of tasks, such as eyeblink conditioning and speech perception and production, in which the timing of brief intervals is a central component. The involvement of the cerebellum in the temporal component of tasks in movement production also depends on the nature of the task. Its role is critical in discontinuous movementsthat is, if there is a need for an explicit representation of the temporal goal. This is not the case, however, in continuous, rhythmic movements (Spencer, Zelaznik, Diedrichsen, \& Ivry, 2003; see also Zelaznik et al., 2008). 
Whether the cerebellum is involved exclusively in the timing of brief intervals or covers a wide duration range is an open question. The cerebellar hypothesis for very brief intervals has been disputed by some authors (Harrington, Lee, Boyd, Rapcsak, \& Knight, 2004). For instance, Nichelli, Always, and Grafman (1996) argued that cerebellar degeneration leads to temporal impairment in a bisection task when intervals to be judged are in the range of a few seconds, but not when they are in the quartersecond range. Additionally, Tracy, Faro, Mohamed, Pinsk, and Pinus (2000) showed, with neural imaging studies involving duration production, that the cerebellum provides codes for the processing of intervals lasting 12-24 sec. However, other studies based on neuroimaging have shown greater activation of the cerebellum for the discrimination of 600-msec rather than of 3-sec intervals (Lewis \& Miall, 2003a). The cerebellum has also been reported to play a role in both production and discrimination timing tasks in cases in which intervals briefer than $1.2 \mathrm{sec}$ were investigated (Bueti, Walsh, Frith, \& Rees, 2008). Somewhat along the same lines, Lee et al. (2007), using rTMS and a bisection task, reported that the timing of 400 - to 800 -msec intervals was affected by the inhibiting effect of the stimulation, but that the timing of intervals above $1 \mathrm{sec}$ was not. Koch et al. (2007) also reported rTMS data that were consistent with the hypothesis that the cerebellum is essential in the reproduction of brief intervals $(400-600 \mathrm{msec}){ }^{8}$

In brief, many studies on the explicit timing of brief intervals have demonstrated the role of the cerebellum. However, some other experiments have shown that the role of the cerebellum might not be restricted to brief intervals (Tracy et al., 2000), or have even called into question the involvement of the cerebellum in the processing of brief intervals (Nichelli et al., 1996).

\section{Cerebral Cortices}

There are several areas of the cerebral cortex that are reported to be active when temporal intervals are processed. In particular, the frontal and parietal cortices and the supplementary motor area (SMA) are said to have a critical role in timing.

Many recent imaging studies have revealed the involvement of the frontal cortex, particularly the dorsolateral prefrontal cortex, in the processing of brief $(<1 \mathrm{sec})$ intervals (Pouthas et al., 2005; Tregellas, Davalos, \& Rojas, 2006), and in the right hemispheric prefrontal cortex with sub- and suprasecond intervals (Koch, Oliveri, Carlesimo, \& Caltagirone, 2002; Lewis \& Miall, 2006; see also Livesey, Wall, \& Smith, 2007; for a review, see Penney \& Vaitilingam, 2008). This evidence confirms what electrophysiological investigations have already indicated regarding the role of the frontal lobe in the coding of temporal information (see Macar \& Vidal, 2009). For instance, Pouthas, Garnero, Ferrandez, and Renault (2000) used contingent negative variations (CNVs), which are an index of slow potential changes (with negative polarity) when a participant is expecting an event, as a dependent variable, in addition to behavioral measures and a temporal generalization task, which involved comparing the length of a comparison interval with a prememorized 700msec standard interval presented several times (before comparison trials began). They observed that potential changes (CNVs) were clearly linked with the duration to be judged: Electrical activity returned to its normal level earlier when the comparison interval was shorter rather than when the comparison interval was longer (see also Pfeuty, Ragot, \& Pouthas, 2008). Macar, Vidal, and Casini (1999) reported quite similar results with a standard interval lasting $2.5 \mathrm{sec}$. Although the interval to be judged always lasted $2.5 \mathrm{sec}$, the CNV amplitude was larger when the interval was judged as being longer (see Figure 5). This finding is compatible with the idea that the CNV amplitude reflects the accumulation of time information, probably pulses if one refers to the pacemaker-counter device described earlier, with more counted pulses resulting in larger CNV amplitude. In brief, additional findings based on CNV indicate that frontal regions play a critical role in the accumulation of temporal information (Pfeuty, Ragot, \& Pouthas, 2003b), during the building of an interval memory trace (Pfeuty, Ragot, \& Pouthas, 2003a), and during the retention of temporal information (Monfort \& Pouthas, 2003; see also Macar \& Vidal, 2004, 2009).

The involvement of the SMA in timing tasks has been documented mainly in the past 10 years. For instance, its role was identified for the timing of intervals briefer than $1 \mathrm{sec}$ (Ferrandez et al., 2003; Tregellas et al., 2006), as well as for the timing of intervals longer than $1 \mathrm{sec}$ (Jahanshahi, Jones, Dirnberger, \& Frith, 2006; Kudo et al., 2004; Rao, Mayer, \& Harrington, 2001; A. Smith, Taylor, Lidzba, \& Rubia, 2003; see Penney \& Vaitilingam, 2008). The SMA is activated (fMRI) either during a timing task or when an explicit counting task ("one thousand one ..., one thousand two ..."-i.e., a counting rate of approximately one count per second) is performed (Hinton, Harrington, Binder, Durgerian, \& Rao, 2004). The SMA is argued to be part of a striato-cortical pathway (Macar, Anton, Bonnet, \& Vidal, 2004; Macar, Coull, \& Vidal, 2006).

In addition, mounting evidence has emerged recently, from the use of TMS, that the parietal cortex is involved in the processing of temporal intervals (Alexander, Cowey, \& Walsh, 2005). More specifically, rTMS studies have shown that the right posterior parietal cortex has a critical role for timing intervals $(<1 \mathrm{sec})$ marked by either auditory or visual signals (Bueti, Bahrami, \& Walsh, 2008), and for timing longer intervals (Koch, Oliveri, Torriero, $\&$ Caltagirone, 2003). In addition, using fMRI has revealed that the parietal cortex, which acts as an interface between sensory and motor processes, is involved in translating temporal information into action (Bueti, Walsh, et al., 2008). Finally, evidence for the role of the parietal cortex - the right hemisphere - in the estimation of long intervals was also obtained with patients with unilateral neglect (Danckert et al., 2007), whereas N'Diaye, Ragot, Garnero, and Pouthas (2004) reported that there is a potential contribution for both frontal and parietal cortices.

\section{Basal Ganglia and Processes}

There are several subcortical cerebral structures that are reported to be involved in the processing of tempo- 


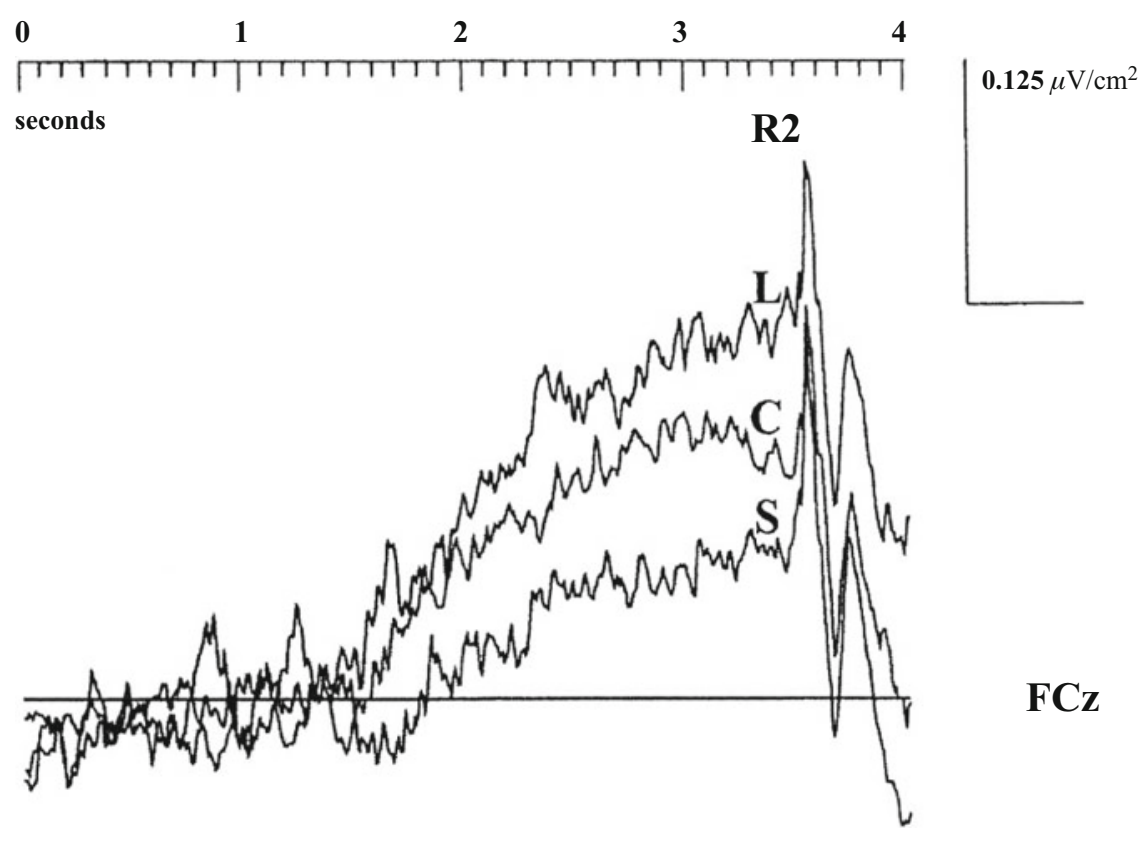

Figure 5. Contingent negative variations obtained over the median frontocentral area (FCz) during the production of a 2.5 -sec target interval. $L$ indicates when a participant's performance is "too long," $C$ when it is "correct," and $S$ when it is "too short." Backward recording time locked to the motor response $(\mathrm{R} 2)$, which terminates the interval. Laplacian estimates, with amplitude (negative up) on ordinate, and time on abscissa. From "EventRelated Potentials As Indices of Time Processing: A Review," by F. Macar \& F. Vidal, 2004, Journal of Psychophysiology, 18, p. 95. Copyright 2004 by the Federation of the European Psychophysiology Society. Reprinted with permission.

ral information. Research using fMRI has demonstrated the involvement of the basal ganglia in the early stages of the timing process - that is, in the encoding of time intervals (Rao et al., 2001; for a review, see Harrington \& Haaland, 1999). It is mainly the caudate and putamen that are shown to be activated by timing tasks. For the processing of subsecond tasks, it is the right part of the caudate nucleus (Jueptner et al., 1995; Pouthas et al., 2005 ) or both this structure and the putamen (Belin et al., 2002; Ferrandez et al., 2003; Tragellas et al., 2006) that are reported to be involved. For the processing of longer intervals $(>1 \mathrm{sec})$, the caudate nucleus (Pouthas et al., 2005), the putamen (Jahanshahi et al., 2006; Livesey et al., 2007; Nenadic et al., 2003), or both (Harrington et al., 2004; Hinton \& Meck, 2004; Nenadic et al., 2003; Rao et al., 2001; Volz et al., 2001) are shown to be active in the timing process.

In the dedicated system perspective (clock process described previously), the timing could be attributed to a distribution of neural activity in the brain. One important model of this sort is the one involving a cortico-striatal or, more specifically, a frontal-striatal, circuitry (Meck \& Benson, 2002; see Matell \& Meck, 2004; Matell, Meck, $\&$ Nicolelis, 2003). The striatum, ${ }^{9}$ which receives millions of impulses from the cortical cells, plays a critical computational role. The hypothesis is that striatal cells receive inputs from cortical neurons when a "start-timing"10 signal is given. These cells, which have firing rates from 10 to 40 cycles per second and are not normally synchronized in their activity, begin firing simultaneously for a moment, creating a specific pattern of neural activity. When the timekeeping activity must stop after a specific time interval, the substantia nigra sends a message to the striatum. The pattern of activation at that moment is then recorded via a burst of dopamine and serves to identify a specific interval length (for a review of the critical role of dopamine on timing, see Rammsayer, 2008).

\section{Summary}

Variations of timing tasks and duration ranges are partly responsible for the difficulty of drawing a clearer and more definitive picture of the brain structures involved in the processing of temporal information. Nevertheless, evidence from different types of neuroscientific methods of investigation indicates that the cerebellum has a computational role in different timing tasks. Furthermore, the prefrontal and parietal cortices, as well as the supplementary motor area, are among the main cortical regions involved in timing and time perception. Finally, the basal ganglia are probably the main subcortical cerebral structures involved in the processing of temporal information.

\section{Conclusion}

Psychological time is a very elusive object of study. We all feel that we have a time sense, but this is certainly not a sense like the others. In daily life, people never or rarely talk about vision or audition in terms of lux, candelas, 
decibels, or hertz. However, we use units (seconds, minutes) to describe time.

Although experimental psychologists have rapidly established a rich history of research on this elusive research topic (Fraisse, 1956, 1957; Roeckelein, 2000, 2008), time perception research has only really blossomed, if not to say exploded, over the past 25 years (see Grondin, 2008b). Much effort has been dedicated to comprehending the impact of the structure of events marking time, and of attention and most recently emotion on time perception. In addition, the past 25 years have seen a multiplication of theoretical propositions, including those embedded within a neuroscience perspective, to account for the ability to process temporal information.

Despite the explosion of research on time perception, there are still critical questions that need to be elucidated. From a strictly behavioral standpoint, we must still try to understand just how reasonable it is to believe that some timing mechanism applies to a large duration range when we know that there are inconstancies in the Weber fraction for time (Grondin, 2001b) and that humans opt to segment intervals when they are asked to keep track of long time intervals. We also know that the general environmental context, through regularity, proximity, or similarity of events, imposes a particular way of understanding time and determines the efficiency of timing performances (M. R. Jones, 1976; M. R. Jones \& Boltz, 1989). This tends to indicate that inner and outer factors determine psychological time, and that the relative importance of these factors may vary with the duration range apprehended.

There could be a multiplicity of timing mechanisms, but one fundamental principle in science is simplicity; viewing the capacity to estimate time in terms of a central, unique, timekeeping device conforms to this principle. This single-clock hypothesis is most often described as a pacemaker-counter device. Its SET version (see Meck, 2003) is very useful for approaching the neuroscientific literature in which some cerebral areas (frontal and parietal cortices and the SMA) and subcortical structures (mainly the basal ganglia) are argued to play critical roles. However, the usefulness of SET should not detract from alternative approaches. One such approach, DAT, emphasizes the important contribution of the structure of the environment (M. R. Jones \& Boltz, 1989) and claims that, ultimately, it is the attunement between this physical reality and internal rhythm states (internal oscillator processes) that determines success in a task involving a critical temporal component (Large \& Jones, 1999). Finally, it cannot be excluded that responsibility for timekeeping is distributed in the brain via some pattern of activity across a neural network and includes specific contributions of neural activity within sensory modalities.

\section{AUTHOR NOTE}

The present research was made possible by a research grant awarded by the Natural Sciences and Engineering Council of Canada (NSERC). I thank Nicolas Bisson, Caroline Gagnon, Howie Zelaznik, and Lorraine Allan for their fine comments on this article. I also extend special thanks to Mari Jones for her numerous local suggestions and her outstanding global review of the article. Correspondence should be addressed to
S. Grondin, École de psychologie, 2325 rue des Bibliothèques, Université Laval, Québec, QC, G1V 0A6 Canada (e-mail: simon.grondin@, psy.ulaval.ca).

\section{REFERENCES}

Alexander, I., Cowey, A., \& Walsh, V. (2005). The right parietal cortex and time perception: Back to Critchley and the Zeitraffer phenomenon. Cognitive Neuropsychology, 22, 306-315. doi:10.1080/ 02643290442000356

Allan, L. G., \& Church, R. M. (EDs.) (2002). Special issue honoring the career of Professor John Gibbon. Learning \& Motivation, 33(1). doi:10.1006/lmot.2001.1114

Allan, L. G., \& GerhardT, K. (2001). Temporal bisection with trial referents. Perception \& Psychophysics, 63, 524-540.

Allan, L. G., \& Kristofferson, A. B. (1974). Psychophysical theories of duration discrimination. Perception \& Psychophysics, 16, 26-34.

Allan, L. G., Kristofferson, A. B., \& Wiens, E. W. (1971). Duration discrimination of brief light flashes. Perception \& Psychophysics, 9, 327-334

Angrilli, A., Cherubini, P., Pavese, A., \& Mantredini, S. (1997). The influence of affective factors on time perception. Perception $\&$ Psychophysics, 59, 972-982.

Arao, H., Suetomi, D., \& Nakajima, Y. (2000). Does time-shrinking take place in visual temporal patterns? Perception, 29, 819-830. doi:10.1068/p2853

BARnes, R., \& Jones, M. R. (2000). Expectancy, attention, and time Cognitive Psychology, 41, 254-311. doi:10.1006/cogp.2000.0738

Belin, P., McAdams, S., Thivard, L., Smith, B., Savel, S., ZilboviCIUS, M., ET AL. (2002). The neuroanatomical substrate of sound duration discrimination. Neuropsychologia, 40, 1956-1964. doi:10.1016/ S0028-3932(02)00062-3

Bendixen, A., Grimm, S., \& Schroger, E. (2006). The relation between onset, offset, and duration perception as examined by psychophysical data and event-related brain potentials. Journal of Psychophysiology, 20, 40-51. doi:10.1027/0269-8803.20.1.40

Bindra, D., \& WAKsberg, H. (1956). Methods and terminology in studies of time estimation. Psychological Bulletin, 53, 155-159. doi: $10.1037 / \mathrm{h} 0041810$

Bisson, N., Tobin, S., \& Grondin, S. (2009). Remembering the duration of joyful and sad musical excerpts. NeuroQuantology, 7, 46-57.

BLock, R. A. (1990). Cognitive models of psychological time. Hillsdale, NJ: Erlbaum.

Block, R. A. (2003). Psychological timing without a timer: The roles of attention and memory. In H. Helfrich (Ed.), Time and mind II (pp. 4160). Göttingen: Hogrefe \& Huber.

BLOCK, R. A., \& ZAKAY, D. (1997). Prospective and retrospective duration judgments: A meta-analytic review. Psychonomic Bulletin \& Review, 4, 184-197.

Block, R. A., \& ZAKAY, D. (2008). Timing and remembering the past, the present, and the future. In S. Grondin (Ed.), Psychology of time (pp. 367-394). Bingley, U.K.: Emerald Group.

Block, R. A., ZAKAY, D., \& HAncock, P. A. (1999). Developmental changes in human duration judgments: A meta-analytic review. Developmental Review, 19, 183-211. doi:10.1006/drev.1998.0475

Boets, B., Wouters, J., van Wieringen, A., \& GHesquière, P. (2006). Auditory temporal information processing in preschool children at family risk for dyslexia: Relations with phonological abilities and developing literacy skills. Brain \& Language, 97, 64-79. doi:10.1016/ j.bandl.2005.07.026

Boltz, M. G. (1992). The remembering of auditory event durations. Journal of Experimental Psychology: Learning, Memory, \& Cognition, 18, 938-956. doi:10.1037/0278-7393.18.5.938

Boltz, M. G. (1994). Changes in internal tempo and effects on the learning and remembering of event durations. Journal of Experimental Psychology: Learning, Memory, \& Cognition, 20, 1154-1171. doi:10.1037/0278-7393.20.5.1154

Boltz, M. G. (1995). Effects of event structure on retrospective duration judgments. Perception \& Psychophysics, 57, 1080-1096.

Boltz, M. G. (2005). Duration judgments of naturalistic events in the auditory and visual modalities. Perception \& Psychophysics, 67, 1362-1375. 
BRAITENBERG, V. (1967). Is the cerebellar cortex a biological clock in the millisecond range? Progress in Brain Research, 25, 334-346.

Brown, S. W. (1997). Attentional resources in timing: Interference effects in concurrent temporal and nontemporal working memory tasks. Perception \& Psychophysics, 59, 1118-1140.

Brown, S. W. (2006). Timing and executive function: Bidirectional interference between concurrent temporal production and randomization tasks. Memory \& Cognition, 34, 1464-1471.

Brown, S. W. (2008). Time and attention: Review of the literature. In S. Grondin (Ed.), Psychology of time (pp. 111-138). Bingley, U.K.: Emerald Group.

Brown, S. W., \& Boltz, M. (2002). Attentional processes in time perception: Effects of mental workload and event structure. Journal of Experimental Psychology: Human Perception \& Performance, 28, 600-615. doi:10.1037/0096-1523.28.3.600

Brown, S. W., \& Merchant, S. M. (2007). Processing resources in timing and sequencing tasks. Perception \& Psychophysics, 69, 439-449.

Brown, S. W., \& STubis, D. A. (1988). The psychophysics of retrospective and prospective timing. Perception, 17, 297-310. doi:10.1068/ p170297

Brown, S. W., Stubbs, D. A., \& West, A. N. (1992). Attention, multiple timing, and psychophysical scaling of temporal judgments. In F. Macar, V. Pouthas \& W. J. Friedman (Eds.), Time, action, and cognition: Towards bridging the gap (pp. 129-140). Dordrecht, The Netherlands: Kluwer.

Brown, S. W., \& West, A. N. (1990). Multiple timing and the allocation of attention. Acta Psychologica, 75, 103-121. doi:10.1016/0001 -6918(90)90081-P

Buccheri, R., SAniga, M., \& Stuckey, M. (Eds.) (2003). The nature of time: Geometry, physics and perception. Dordrecht, The Netherlands: Kluwer.

Bueti, D., Bahrami, B., \& Walsh, V. (2008). Sensory and associative cortex in time perception. Journal of Cognitive Neuroscience, 20, 1054-1062. doi:10.1162/jocn.2008.20060

Bueti, D., Walsh, V., Frith, C., \& Rees, G. (2008). Different brain circuits underlie motor and perceptual representations of temporal intervals. Journal of Cognitive Neuroscience, 20, 204-214. doi:10.1162/ jocn.2008.20017

BuHusi, C. V., \& Meck, W. H. (2005). What makes us tick? Functional and neural mechanisms of interval timing. Nature Reviews Neuroscience, 6, 755-765. doi:10.1038/nrn1764

Buhusi, C. V., \& Meck, W. H. (2009). Relative time sharing: New findings and an extension of the resource allocation model of temporal processing. Philosophical Transactions of the Royal Society B, 364, $1875-1885$.

Buonomano, D. V. (2007). The biology of time across different scales. Nature Chemical Biology, 3, 594-597.

Burle, B., \& CAsini, L. (2001). Dissociation between activation and attention effects in time estimation: Implications for internal clock models. Journal of Experimental Psychology: Human Perception \& Performance, 27, 195-205. doi:10.1037/0096-1523.27.1.195

Burr, D., Tozzi, A., \& Morrone, M. C. (2007). Neural mechanisms for timing visual events are spatially selective in real-world coordinates. Nature Neuroscience, 10, 423-425. doi:10.1038/nn1874

Carroll, C. A., O’Donnell, B. F., Shekhar, A., \& Hetrick, W. P. (2009). Timing dysfunctions in schizophrenia span from millisecond to several-second durations. Brain \& Cognition, 70, 181-190. doi:10.1016/j.bandc.2009.02.001

Caruso, E. M., Gilbert, D. T., \& Wilson, T. D. (2008). A wrinkle in time: Asymmetric valuation of past and future events. Psychological Science, 19, 796-801. doi:10.1111/j.1467-9280.2008.02159.x

CASINI, L., \& MACAR, F. (1997). Effects of attention manipulation on judgments of duration and of intensity in the visual modality. Memory \& Cognition, 25, 812-818.

Chambon, M., Gil, S., Niedenthal, P. M., \& Droit-Volet, S. (2005). Psychologie sociale et perception du temps: l'estimation temporelle des stimuli sociaux et émotionnels [Social psychology and time perception: The temporal estimation of social and emotional stimuli]. Psychologie Française, 50, 167-180. doi:10.1016/j.psfr.2004.10.008

Church, R. M. (1997). Timing and temporal search. In C. M. Bradshaw \& E. Szabadi (Eds.), Time and behavior: Psychological and neurobehavioral analyses (pp. 41-78). Amsterdam: Elsevier, North-Holland.

Church, R. M. (2003). A concise introduction to the scalar timing theory. In W. H. Meck (Ed.), Functional and neural mechanisms of interval timing (pp. 3-22). Boca Raton, FL: CRC.

Church, R. M., \& Broadbent, H. A. (1990). Alternative representations of time, number, and rate. Cognition, 37, 55-81. doi:10.1016/0010 $-0277(90) 90018-\mathrm{F}$

Coull, J. T., Vidal, F., Nazarian, B., \& Macar, F. (2004). Functional anatomy of the attentional modulation of time estimation. Science, 303, 1506-1508.

Creelman, C. D. (1962). Human discrimination of auditory duration. Journal of the Acoustical Society of America, 34, 582-593. doi:10 $.1121 / 1.1918172$

Crystal, J. D. (ED.) (2007). The psychology of time: A tribute to the contributions of Russell M. Church [Special Issue]. Behavioural Processes, 74(2).

Damasio, A. R. (2002). Remembering when. Scientific American, 287, 66-73.

Danckert, J., Ferber, S., Pun, C., Broderick, C., Striemer, C., Rock, S., \& STEWART, D. (2007). Neglected time: Impaired temporal perception of multisecond intervals in unilateral neglect. Journal of Cognitive Neuroscience, 19, 1706-1720. doi:10.1162/jocn.2007.19.10.1706

Davalos, D. B., Kisley, M. A., \& Freedman, R. (2005). Behavioral and electrophysiological indices of temporal processing dysfunction in schizophrenia. Journal of Neuropsychiatry \& Clinical Neurosciences, 17, 517-525.

Davalos, D. B., Kisley, M. A., Polk, S. D., \& Ross, R. G. (2003). Mismatch negativity in detection of interval duration deviation in schizophrenia. Cognitive Neuroscience \& Neuropsychology, 14, 1283-1286. doi:10.1097/00001756-200307010-00019

Davalos, D. B., Kisley, M. A., \& Ross, R. G. (2002). Deficits in auditory and visual temporal perception in schizophrenia. Cognitive Neuropsychiatry, 7, 273-282. doi:10.1080/13546800143000230

Davalos, D. B., Kisley, M. A., \& Ross, R. G. (2003). Effects of interval duration on temporal processing in schizophrenia. Brain \& Cognition, 52, 295-301. doi:10.1016/S0278-2626(03)00157-X

Drake, C., \& Botte, M.-C. (1993). Tempo sensitivity in auditory sequences: Evidence for a multiple-look model. Perception \& Psychophysics, 54, 277-286.

Droit-Volet, S., Brunot, S., \& Niedenthal, P. M. (2004). Perception of the duration of emotional events. Cognition \& Emotion, 18, 849858. doi:10.1080/02699930341000194

Droit-Volet, S., \& GiL, S. (2009). Emotion and time perception. Philosophical Transactions of the Royal Society B, 364, 1943-1953.

Droit-Volet, S., \& MeCK, W. H. (2007). How emotions colour our perception of time. Trends in Cognitive Sciences, 11, 504-513. doi:10.1016/j.tics.2007.09.008

Droit-Volet, S., Meck, W. H., \& Penney, T. B. (2007). Sensory modality and time perception in children and adults. Behavioural Processes, 74, 244-250. doi:10.1016/j.beproc.2006.09.012

Droit-Volet, S., Wearden, J. H., \& Delgado, M. D. (2007). Shortterm memory for time in children and adults: A behavioral study and a model. Journal of Experimental Child Psychology, 97, 246-264. doi:10.1016/j.jecp.2007.02.003

Eagleman, D. M. (2008). Human time perception and its illusions. Current Opinion in Neurobiology, 18, 131-136. doi:10.1016/j.conb.2008 .06 .002

Edwards, V. T., Giaschi, D. E., Dougherty, R. F., Edgell, D., BJornson, B. H., Lyons, C., \& Douglas, R. M. (2004). Psychophysical indexes of temporal processing abnormalities in children with developmental dyslexia. Developmental Neuropsychology, 25, 321-354. doi:10.1207/s15326942dn2503_5

Effron, D. A., Niedenthal, P. M., Gil, S., \& Droit-Volet, S. (2006). Embodied temporal perception of emotion. Emotion, 6, 1-9. doi: $10.1037 / 1528-3542.6 .1 .1$

Eisler, A. D., Eisler, H., \& Montgomery, H. (2004). A quantitative model for retrospective subjective duration. NeuroQuantology, $\mathbf{4}$, 263-291.

EISLER, H. (1975). Subjective duration and psychophysics. Psychological Review, 82, 429-450. doi:10.1037/0033-295X.82.6.429

EISLER, H. (1976). Experiments on subjective duration 1878-1975: A collection of power function exponents. Psychological Bulletin, 83, 1154-1171. doi:10.1037/0033-2909.83.6.1154

EISLER, H. (2003). The parallel-clock model: A tool for quantification of experienced duration. In R. Buccheri, M. Saniga, \& M. Stuckey 
(Eds.), The nature of time: Geometry, physics and perception (pp. 1926). Dordrecht, The Netherlands: Kluwer.

EISLER, H., \& EISLER, A. D. (1992). Time perception: Effects of sex and sound intensity on scales of subjective duration. Scandinavian Journal of Psychology, 33, 339-358. doi:10.1111/j.1467-9450.1992 .tb00923.x

Eisler, H., Eisler, A. D., \& Hellström, Å. (2008). Psychophysical issues in the study of time perception. In S. Grondin (Ed.), Psychology of time (pp. 75-110). Bingley, U.K.: Emerald Group.

Elvevåg, B., Brown, G. D. A., McCormack, T., Vousden, J. I., \& GoldBERG, T. E. (2004). Identification of tone duration, line length, and letter position: An experimental approach to timing and working memory deficits in schizophrenia. Journal of Abnormal Psychology, 113, 509-521. doi:10.1037/0021-843X.113.4.509

Elvevi̊g, B., McCormack, T., Gilbert, A., Brown, G. D. A., WeinBERGER, D. R., \& GoldBERG, T. E. (2003). Duration judgments in patients with schizophrenia. Psychological Medicine, 33, 1249-1261.

Ferrandez, A. M., Hugueville, L., Lehericy, S., Poline, J. B., MarSault, C., \& Pouthas, V. (2003). Basal ganglia and supplementary motor area subtend duration perception: An fMRI study. NeuroImage, 19, 1532-1544

Field, D. T., \& Groeger, J. A. (2004). Temporal interval production and short-term memory. Perception \& Psychophysics, 66, 808-819.

Ford, M. P., Wagenaar, R. C., \& Newell, K. M. (2007). The effects of auditory rhythms and instruction on walking patterns in individuals post stroke. Gait \& Posture, 26, 150-155.

Fortin, C., Bédard, M.-C., \& Champagne, J. (2005). Timing during interruptions in timing. Journal of Experimental Psychology: Human Perception \& Performance, 31, 276-288. doi:10.1037/0096 $-1523.31 .2 .276$

Fortin, C., Fairhurst, S., Malapani, C., Morin, C., Towey, J., \& MecK, W. H. (2009). Expectancy in humans in multisecond peakinterval timing with gaps. Attention, Perception, \& Psychophysics, 71, 789-802.

FraISSE, P. (1956). Les structures rythmiques [Rhythmic structures]. Louvain, Belgium: Studia Psychologica.

Fraisse, P. (1957). Psychologie du temps [Psychology of time]. Paris: Presses Universitaires de France.

Fraisse, P. (1978). Time and rhythm perception. In E. Carterette \& M. Friedman (Eds.), Handbook of perception: Vol. 8. Perceptual coding (pp. 203-254). New York: Academic Press.

FraIsSe, P. (1984). Perception and estimation of time. Annual Review of Psychology, 35, 1-36.

Frassinetti, F., Magnani, B., \& Oliveri, M. (2009). Prismatic lenses shift time perception. Psychological Science, 20, 949-954. doi:10.1111/j.1467-9280.2009.02390.x

Friberg, A., \& SundBerg, J. (1995). Time discrimination in a monotonic, isochronic sequence. Journal of the Acoustical Society of America, 98, 2524-2531. doi:10.1121/1.413218

Friedman, W. J. (1993). Memory for the time of past events. Psychological Bulletin, 113, 44-66. doi:10.1037/0033-2909.113.1.44

Friedman, W. J. (2008). Developmental perspectives on the psychology of time. In S. Grondin (Ed.), Psychology of time (pp. 345-366). Bingley, U.K.: Emerald Group.

Gamache, P.-L., \& Grondin, S. (2008). Temporal limits of memory for time. In B. Schneider, B. M. Ben-David, S. Parker, \& W. Wong (Eds.), Fechner Day 2008: Proceedings of the 24th Annual Meeting of the ISP (pp. 173-178). Toronto: The ISP.

GibBon, J. (1977). Scalar expectancy theory and Weber's law in animal timing. Psychological Review, 84, 279-325.

Gibbon, J. (1991). Origins of scalar timing. Learning \& Motivation, 22, 3-38. doi:10.1016/0023-9690(91)90015-Z

GibBon, J. (1992). Ubiquity of scalar timing with a Poisson clock. Journal of Mathematical Psychology, 36, 283-293. doi:10.1016/0022 $-2496(92) 90041-5$

Gibbon, J., Church, R. M., \& Meck, W. H. (1984). Scalar timing in memory. In J. Gibbon \& L. Allan (Eds.), Timing and time perception (Annals of the New York Academy of Sciences, Vol. 423, pp. 52-77). New York: New York Academy of Sciences.

Gil, S., Niedenthal, P. M., \& Droit-Volet, S. (2007). Anger and time perception in children. Emotion, 7, 219-225. doi:10.1037/1528 $-3542.7 .1 .219$
Gilden, D. L., \& Marusich, L. R. (2009). Contraction of time in attention-deficit hyperactivity disorder. Neuropsychology, 23, 265269. doi: $10.1037 / \mathrm{a} 0014553$

GLICKsOHN, J. (2001). Temporal cognition and the phenomenology of time: A multiplicative function for apparent duration. Consciousness \& Cognition, 10, 1-25. doi: 10.1006/ccog.2000.0468

Glicksohn, J., \& Cohen, Y. (2000). Can music alleviate cognitive dysfunction in schizophrenia? Psychopathology, 33, 43-47. doi:10.1159/ 000029118

Glicksohn, J., \& Myslobodsky, M. S. (Eds.) (2006). Timing the future: The case for a time-based prospective memory. London: World Scientific Publishing.

GoldReICH, D. (2007). A Bayesian perceptual model replicates the cutaneous rabbit and other tactile spatiotemporal illusions. PLOS ONE, 2, e333. doi:10.1371/journal.pone.0000333

Goldstone, S., \& Lhamon, W. T. (1974). Studies of auditory-visual differences in human time judgment: I. Sounds are judged longer than lights. Perceptual \& Motor Skills, 39, 63-82.

Grondin, S. (1993). Duration discrimination of empty and filled intervals marked by auditory and visual signals. Perception \& Psychophysics, 54, 383-394.

Grondin, S. (2001a). Discriminating time intervals presented in sequences marked by visual signals. Perception \& Psychophysics, 63, 1214-1228.

Grondin, S. (2001b). From physical time to the first and second moments of psychological time. Psychological Bulletin, 127, 22-44. doi:10.1037/0033-2909.127.1.22

Grondin, S. (2001c). A temporal account of the limited processing capacity. Behavioral \& Brain Sciences, 24, 122-123.

Grondin, S. (2003). Sensory modalities and temporal processing. In H. Helfrich (Ed.), Time and mind II (pp. 61-77). Göttingen: Hogrefe \& Huber.

Grondin, S. (2005). Overloading temporal memory. Journal of Experimental Psychology: Human Perception \& Performance, 31, 869-879. doi:10.1037/0096-1523.31.5.869

Grondin, S. (2008a). Methods for studying psychological time. In S. Grondin (Ed.), Psychology of time (pp. 51-74). Bingley, U.K.: Emerald Group.

Grondin, S. (ED.) (2008b). Psychology of time. Bingley, U.K.: Emerald Group.

Grondin, S., Bisson, N., Gagnon, C., Gamache, P.-L., \& Matteau, A.-A. (2009). Little to be expected from auditory training for improving visual temporal discrimination. NeuroQuantology, 7, 95-102.

Grondin, S., Dionne, G., Malenfant, N., Plourde, M., Cloutier, M.-E., \& JeAN, C. (2007). Temporal processing skills of children with and without specific language impairment. Canadian Journal of Speech-Language Pathology \& Audiology, 31, 38-46.

Grondin, S., Gamache, P.-L., Tobin, S., Bisson, N., \& Hawke, L. (2008). Categorization of brief temporal intervals: An auditory processing context may impair visual performances. Acoustical Science \& Technology, 29, 338-340.

Grondin, S., \& Killeen, P. R. (2009). Tracking time with song and count: Different Weber functions for musicians and nonmusicians. Attention, Perception, \& Psychophysics, 71, 1649-1654.

Grondin, S., \& MaCAR, F. (1992). Dividing attention between temporal and nontemporal tasks: A performance operating characteristicPOC - analysis. New York: Kluwer Academic/Plenum.

Grondin, S., \& McAuley, J. D. (2009). Duration discrimination in crossmodal sequences. Perception, 38, 1542-1559.

Grondin, S., Meilleur-Wells, G., \& Lachance, R. (1999). When to start explicit counting in a time-intervals discrimination task: Acritical point in the timing process of humans. Journal of Experimental Psychology: Human Perception \& Performance, 25, 993-1004. doi:10.1037/0096-1523.25.4.993

Grondin, S., Ouellet, B., \& Roussel, M.-E. (2004). Benefits and limits of explicit counting for discriminating temporal intervals. Canadian Journal of Experimental Psychology, 58, 1-12. doi:10.1037/ h0087436

Grondin, S., \& Plourde, M. (2007a). Discrimination of time intervals presented in sequences: Spatial effects with multiple auditory sources. Human Movement Science, 26, 702-716. doi:10.1016/j.humov.2007 .07 .009 
Grondin, S., \& Plourde, M. (2007b). Judging multi-minute intervals retrospectively. Quarterly Journal of Experimental Psychology, 60, 1303-1312. doi:10.1080/17470210600988976

Grondin, S., Pouthas, V., Samson, S., \& Roy, M. (2006). Mécanismes et désordres liés à l'adaptation au temps [Mechanisms and disorders related to the adaptation to time]. Canadian Psychology, 47, 170-183. doi: $10.1037 / \mathrm{cp} 2006007$

Grondin, S., \& RAmmsayer, T. (2003). Variable foreperiods and temporal discrimination. Quarterly Journal of Experimental Psychology, 56A, 731-765. doi:10.1080/02724980244000611

Grondin, S., \& Rousseau, R. (1991). Judging the relative duration of multimodal short empty time intervals. Perception \& Psychophysics, 49, 245-256.

Grondin, S., Roussel, M.-E., Gamache, P.-L., Roy, M., \& Ouellet, B. (2005). The structure of sensory events and the accuracy of time judgments. Perception, 34, 45-58. doi:10.1068/p5369

Guillot, A., \& Collet, C. (2005). Duration of mentally simulated movement: A review. Journal of Motor Behavior, 37, 10-20. doi:10.3200/JMBR.37.1.10-20

Handy, T. C., Gazzaniga, M. S., \& Ivry, R. B. (2003). Cortical and subcortical contributions to the representation of temporal information. Neuropsychologia, 41, 1461-1473. doi:10.1016/S0028 -3932(03)00093-9

Harrington, D. L., \& HaAland, K. Y. (1999). Neural underpinnings of temporal processing: A review of focal lesion, pharmacological, and functional imaging research. Reviews in the Neurosciences, 10, 91-116.

Harrington, D. L., LeE, R. R., Boyd, L. A., RapcsaK, S. Z., \& KNight, R. T. (2004). Does the representation of time depend on the cerebellum? Effect of cerebellar stroke. Brain, 127, 1-14. doi:10.1093/brain/ awh065

Hecht, H., \& Savelsbergh, G. (Eds.) (2004). Time-to-contact (Advances in Psychology, Vol. 135). Amsterdam: Elsevier, North-Holland.

Helfrich, H. (ED.) (2003). Time and mind II: Information processing perspectives. Seattle: Hogrefe \& Huber.

Hellström, Å. (1985). The time-order error and its relatives: Mirrors of cognitive processes in comparing. Psychological Bulletin, 97, 35-61. doi:10.1037/0033-2909.97.1.35

Hellström, A., \& Rammsayer, T. H. (2004). Effects of time-order, interstimulus interval, and feedback in duration discrimination of noise bursts in the 50- and 1000-ms ranges. Acta Psychologica, 116, 1-20. doi:10.1016/j.actpsy.2003.11.003

Helson, H. (1964). Adaptation-level theory. New York: Harper \& Row.

Hemmes, N. S., Brown, B. L., \& Kladopoulos, C. N. (2004). Time perception with and without a concurrent nontemporal task. Perception \& Psychophysics, 66, 328-341.

Henry, M. J., \& McAuley, J. D. (2009). Evaluation of an imputed pitch velocity model of the auditory kappa effect. Journal of Experimental Psychology: Human Perception \& Performance, 35, 551-564. doi:10.1037/0096-1523.35.2.551

Henry, M. J., McAuley, J. D., \& Zaleha, M. (2009). Perceived pitch depends on perceived time: Further test of an auditory motion hypothesis. Attention, Perception, \& Psychophysics, 71, 1399-1413.

Hicks, R. E., Miller, G. W., \& Kinsbourne, M. (1976). Prospective and retrospective judgments of time as a function of amount of information processed. American Journal of Psychology, 89, 719-730. doi: $10.2307 / 1421469$

Hinton, S. C., Harrington, D. L., Binder, J. R., Durgerian, S., \& RAO, S. M. (2004). Neural systems supporting timing and chronometric counting: An FMRI study. Cognitive Brain Research, 21, 183-192. doi:10.1016/j.cogbrainres.2004.04.009

Hinton, S. C., \& MEcK, W. H. (2004). Frontal-striatal circuitry activated by human peak-interval timing in the supra-seconds range. Cognitive Brain Research, 21, 171-182. doi:10.1016/j.cogbrainres.2004.08.005

Hinton, S. C., \& Rao, S. M. (2004). "One-thousand one . . onethousand two ...": Chronometric counting violates the scalar property in interval timing. Psychonomic Bulletin \& Review, 11, 24-30.

Hirsh, I. J., Monahan, C. B., Grant, K. W., \& Singh, P. G. (1990). Studies in auditory timing: 1 . Simple patterns. Perception \& Psychophysics, 47, 215-226.

Hirsh, I. J., \& Sherrick, C. E. (1961). Perceived order in different sense modalities. Journal of Experimental Psychology, 62, 423-432. doi:10.1037/h0045283
Hodinott-Hill, I., Thilo, K. V., Cowey, A., \& Walsh, V. (2002). Auditory chronostasis: Hanging on the telephone. Current Biology, 12, 1779-1781. doi:10.1016/S0960-9822(02)01219-8

Hopson, J. W. (2003). General learning models: Timing without a clock. In W. H. Meck (Ed.), Functional and neural mechanisms of interval timing (pp. 23-60). Boca Raton, FL: CRC.

HorNIK, J. (1992). Time estimation and orientation mediated by transient mood. Journal of Socio-Economics, 21, 209-227. doi:10.1016/1053 $-5357(92) 90010-5$

IVry, R. B., \& Hazeltine, R. E. (1995). The perception and production of temporal intervals across a range of durations: Evidence for a common timing mechanism. Journal of Experimental Psychology: Human Perception \& Performance, 21, 3-18. doi:10.1037/0096-1523.21.1.3

IVRY, R. B., \& KeELE, S. W. (1989). Timing functions of the cerebellum. Journal of Cognitive Neuroscience, 1, 136-152. doi:10.1162/ jocn.1989.1.2.136

IVry, R. B., Keele, S. W., \& Diener, H. C. (1988). Dissociation of the lateral and medial cerebellum in movement timing and movement execution. Experimental Brain Research, 73, 167-180.

IVRY, R. B., \& RichaRdSON, T. C. (2002). Temporal control and coordination: The multiple timer model. Brain \& Cognition, 48, 117-132. doi:10.1006/brcg.2001.1308

IVRY, R. B., \& SCHLERF, J. (2008). Dedicated and intrinsic models of time perception. Trends in Cognitive Sciences, 12, 273-280. doi:10.1016/ j.tics.2008.04.002

Jahanshahi, M., Jones, C. R. G., Dirnberger, G., \& Frith, C. D. (2006). The substantia nigra pars compacta and temporal processing. Journal of Neuroscience, 26, 12266-12273. doi:10.1523/JNEUROSCI .2540-06.2006

JAMES, W. (1890). The principles of psychology. New York: Holt.

Jantzen, K. J., Steinberg, F. L., \& Kelso, J. A. S. (2005). Functional MRI reveals the existence of modality and coordination-dependent timing networks. NeuroImage, 25, 1031-1042.

Johnston, A., Arnold, D. H., \& Nishida, S. (2006). Spatially localized distortions of event time. Current Biology, 16, 472-479.

Jones, B., \& HuAng, Y. L. (1982). Space-time dependencies in psychophysical judgment of extent and duration: Algebraic models of the tau and kappa effects. Psychological Bulletin, 91, 128-142. doi:10.1037/0033-2909.91.1.128

Jones, L. A., \& WeARden, J. H. (2003). More is not necessarily better: Examining the nature of the temporal reference memory component in timing. Quarterly Journal of Experimental Psychology, 56B, 321343. doi:10.1080/02724990244000287

Jones, L. A., \& Wearden, J. H. (2004). Double standards: Memory loading in temporal reference memory. Quarterly Journal of Experimental Psychology, 57B, 55-77. doi:10.1080/02724990344000088

JoNES, M. R. (1976). Time, our lost dimension: Toward a new theory of perception, attention, and memory. Psychological Review, 83, 323355. doi:10.1037/0033-295X.83.5.323

Jones, M. R., \& Boltz, M. (1989). Dynamic attending and responses to time. Psychological Review, 96, 459-491. doi:10.1037/0033-295X 96.3.459

Jones, M. R., Johnston, H. M., \& Puente, J. (2006). Effects of auditory pattern structure on anticipatory and reactive attending. Cognitive Psychology, 53, 59-96. doi:10.1016/j.cogpsych.2006.01.003

Jones, M. R., \& McAuley, J. D. (2005). Time judgments in global temporal contexts. Perception \& Psychophysics, 67, 398-417.

Jueptner, M., Rijntjes, M., Weiller, C., Faiss, J. H., Timmann, D., Mueller, S. P., \& Diener, H. C. (1995). Localization of a cerebellar timing process using PET. Neurology, 45, 1540-1545.

Kanai, R., \& Watanabe, M. (2006). Visual onset expands subjective time. Perception \& Psychophysics, 68, 1113-1123.

Karmarkar, U. R., \& Buonomano, D. V. (2007). Timing in the absence of clocks: Encoding time in neural network states. Neuron, 53, 427-438.

KeELE, S. W., \& Ivry, R. B. (1991). Does the cerebellum provide a common computation for diverse tasks? A timing hypothesis. In A. Diamond (Ed.), The developmental and neural bases of higher cognitive functions (Annals of the New York Academy Sciences, Vol. 608, pp. 179-211). New York: New York Academy of Sciences.

Keele, S. W., Pokorny, R. A., Corcos, D. M., \& Ivry, R. (1985). Do perception and motor production share common timing mech- 
anisms: A correlational analysis. Acta Psychologica, 60, 173-191. doi:10.1016/0001-6918(85)90054-X

Kellaris, J. J., \& Kent, R. J. (1992). The influence of music on consumers' temporal perceptions: Does time fly when you're having fun? Journal of Consumer Psychology, 1, 365-376. doi:10.1016/S1057 $-7408(08) 80060-5$

Killeen, P. R., \& Fetterman, J. G. (1988). A behavioral theory of timing. Psychological Review, 95, 274-295. doi:10.1037/0033-295X.95 .2 .274

Killeen, P. R., Fetterman, J. G., \& Bizo, L. A. (1997). Time's cause. In C. M. Bradshaw \& E. Szabadi (Eds.), Time and behavior: Psychological and neurobehavioral analyses (pp. 79-131). Amsterdam: Elsevier, North-Holland.

Killeen, P. R., \& TAYlor, T. J. (2000). How the propagation of error through stochastic counters affects time discrimination and other psychophysical judgments. Psychological Review, 107, 430-459.

Killeen, P. R., \& Weiss, N. A. (1987). Optimal timing and the Weber function. Psychological Review, 94, 455-468. doi:10.1037/0033 $-295 X .107 .3 .430$

KLApproth, F. (2009). Single-modality memory mixing in temporal generalization: An effect due to instructional ambiguity. NeuroQuantology, 7, 85-94

Koch, G., Oliveri, M., Carlesimo, G. A., \& Caltagirone, C. (2002). Selective deficit of time perception in a patient with right prefrontal cortex lesion. Neurology, 59, 1658-1659.

Koch, G., Oliveri, M., Torriero, S., \& Caltagirone, C. (2003). Underestimation of time perception after repetitive transcranial magnetic stimulation. Neurology, 60, 1844-1846.

Koch, G., Oliveri, M., Torriero, S., Salerno, S., Lo Gerfo, E. \& Caltagirone, C. (2007). Repetitive TMS of cerebellum interferes with millisecond time processing. Experimental Brain Research, 179, 291-299.

Kudo, K., Miyazaki, M., Kimura, T., Yamanaka, K., Kadota, H., Hirashima, M., ET AL. (2004). Selective activation and deactivation of the human brain structures between speeded and precisely timed tapping responses to identical visual stimulus: An fMRI study. NeuroImage, 22, 1291-1301.

Labelle, M.-A., Graf, P., Grondin, S., \& Gagné-Roy, L. (2009). Time-related processes in time-based prospective memory and in time-interval production. European Journal of Cognitive Psychology, 21, 501-521. doi:10.1080/09541440802031000

LAPID, E., Ulrich, R., \& RAMmSAYer, T. (2008). On estimating the difference limen in duration discrimination tasks: A comparison of the $2 \mathrm{AFC}$ and the reminder tasks. Perception \& Psychophysics, 70, 291-305. doi:10.3758/PP.70.2.291

LAPID, E., Ulrich, R., \& Rammsayer, T. (2009). Perceptual learning in auditory temporal discrimination: No evidence for a cross-modal transfer to the visual modality. Psychonomic Bulletin \& Review, 16, 382-389.

LARGE, E. W. (2008). Resonating to musical rhythm: Theory and experiment. In S. Grondin (Ed.), Psychology of time (pp. 189-232). Bingley, U.K.: Emerald Group.

LARGe, E. W., \& Jones, M. R. (1999). The dynamics of attending: How we track time varying events. Psychological Review, 106, 119-159.

LAVOIE, P., \& GRONDIN, S. (2004). Information processing limitations as revealed by temporal discrimination. Brain \& Cognition, 54, 198-200. doi:10.1016/j.bandc.2004.02.039

Lee, K. H., Bhaker, R. S., Mysore, A., Parks, R. W., Birkett, P. B., \& Woodruff, P. W. (2009). Time perception and its neuropsychological correlates in patients with schizophrenia and in healthy volunteers. Psychiatry Research, 166, 174-183.

Lee, K. H., Eagleston, P. N., Brown, W. H., Gregory, A.N., Barker, A. T., \& Woodruff, P. W. R. (2007). The role of the cerebellum in subsecond time perception: Evidence from repetitive transcranial magnetic stimulation. Journal of Cognitive Neuroscience, 19, 147157. doi:10.1162/jocn.2007.19.1.147

LeJeune, H., \& WEARDEN, J. H. (2009). Vierordt's The experimental study of the time sense (1868) and its legacy. European Journal of Cognitive Psychology, 21, 941-960.

Lewis, P. A., \& Miall, R. C. (2003a). Brain activation patterns during measurement of sub- and supra-second intervals. Neuropsychologia, 41, 1583-1592. doi:10.1016/S0028-3932(03)00118-0

Lewis, P. A., \& Miall, R. C. (2003b). Distinct systems for automatic and cognitively controlled time measurement: Evidence from neuroimaging. Current Opinion in Neurobiology, 13, 250-255. doi:10.1016 S0959-4388(03)00036-9

Lewis, P. A., \& Miall, R. C. (2006). A right hemispheric prefrontal system for cognitive time measurement. Behavioural Processes, 71, 226-234. doi:10.1016/j.beproc.2005.12.009

LEWIS, P. A., \& Miall, R. C. (2009). The precision of temporal judgement: Milliseconds, many minutes, and beyond. Philosophical Transactions of the Royal Society B, 364, 1897-1905.

Lhamon, W. T., \& Goldstone, S. (1974). Studies on auditory-visual differences in human time judgment: II. More transmitted information with sounds than lights. Perceptual \& Motor Skills, 39, 295-307.

Livesey, A. C., Wall, M. B., \& Smith, A. T. (2007). Time perception: Manipulation of task difficulty dissociates clock functions from other cognitive demands. Neuropsychologia, 45, 321-331. doi:10.1016/ j.neuropsychologia.2006.06.033

Lobo, F. S. N. (2008). Nature of time and causality in physics. In S. Grondin (Ed.), Psychology of time (pp. 395-422). Bingley, U.K. Emerald Group.

Macar, F., Anton, J.-L., Bonnet, M., \& Vidal, F. (2004). Timing functions of the supplementary motor area: An event-related fMRI study. Cognitive Brain Research, 21, 206-215. doi:10.1016/ j.cogbrainres.2004.01.005

Macar, F., Coull, J., \& Vidal, F. (2006). The supplementary motor area in motor and perceptual time processing: fMRI studies. Cognitive Processing, 7, 89-94. doi:10.1007/s10339-005-0025-7

Macar, F., Grondin, S., \& CASINI, L. (1994). Controlled attention sharing influences time estimation. Memory \& Cognition, 22, 673-686.

Macar, F., Lejeune, H., Bonnet, M., Ferrara, A., Pouthas, V., Vidal, F., \& Maquet, P. (2002). Activation of the supplementary motor area and of attentional networks during temporal processing. Experimental Brain Research, 142, 475-485.

MACAR, F., \& VidAL, F. (2004). Event-related potentials as indices of time processing: A review. Journal of Psychophysiology, 18, 89-104. doi:10.1027/0269-8803.18.23.89

MacAR, F., \& Vidal, F. (2009). Timing processes: An outline of behavioural and neural indices not systematically considered in timing models. Canadian Journal of Experimental Psychology, 63, 227-239. doi:10.1037/a0014457

MacAR, F., VidAl, F., \& CASini, L. (1999). The supplementary motor area in motor and sensory timing: Evidence from slow brain potential changes. Experimental Brain Research, 135, 271-280.

Macmillan, N. A., \& Creelman, C. D. (1991). Detection theory: A user's guide. New York: Cambridge University Press.

MADISON, G. (2001). Variability in isochronous tapping: Higher order dependencies as a function of intertap interval. Journal of Experimental Psychology: Human Perception \& Performance, 27, 411-422. doi:10.1037/0096-1523.27.2.411

Marzi, C. A. (2004). Two brains, one clock. Trends in Cognitive Sciences, 8, 1-3. doi:10.1016/j.tics.2003.10.015

Matell, M. S., \& MecK, W. H. (2004). Cortico-striatal circuits and interval timing: Coincidence detection of oscillatory processes. Cognitive Brain Research, 21, 139-170. doi:10.1016/j.cogbrainres.2004.06.012

Matell, M. S., MecK, W. H., \& Nicolelis, M. A. L. (2003). Integration of behavior and timing: Anatomically separate system or distributed processing? In W. H. Meck (Ed.), Functional and neural mechanisms of interval timing (pp. 485-514). Boca Raton, FL: CRC.

Mauk, M. D., \& Buonomano, D. V. (2004). The neural basis of temporal processing. Annual Review of Neuroscience, 27, 307-340. doi:10 1146/annurev.neuro.27.070203.144247

McAuley, J. D., \& Jones, M. R. (2003). Modeling effects of rhythmic context on perceived duration: A comparison of interval and entrainment approaches to short-interval timing. Journal of Experimental Psychology: Human Perception \& Performance, 29, 1102-1125. doi:10.1037/0096-1523.29.6.1102

McAuley, J. D., Jones, M. R., Holub, S., Johnston, H. M., \& MilLER, N. S. (2006). The time of our lives: Life span development of timing and event tracking. Journal of Experimental Psychology: General, 135, 348-367. doi:10.1037/0096-3445.135.3.348

McAuley, J. D., \& Miller, N. S. (2007). Picking up the pace: Effects of global temporal context on sensitivity to the tempo of auditory sequences. Perception \& Psychophysics, 69, 709-718.

McCormack, T., Wearden, J., Smith, M., \& Brown, G. (2005). Epi- 
sodic temporal generalization: A developmental study. Quarterly Journal of Experimental Psychology, 58A, 693-704. doi:10.1080/ 02724980443000250

Меск, W. H. (1984). Attentional bias between modalities: Effect on the internal clock, memory, and decision stages used in animal time discrimination. In J. Gibbon \& L. G. Allan (Eds.), Timing and time perception (Annals of the New York Academy of Sciences, Vol. 423, pp. 528-541). New York: New York Academy of Sciences.

MECK, W. H. (ED.) (2003). Functional and neural mechanisms of internal timing. Boca Raton, FL: CRC.

MecK, W. H. (ED.) (2004). Neuroimaging of interval timing [Special issue]. Cognitive Brain Research, 21(2). doi:10.1016/j.cogbrainres .2004 .07 .010

MECK, W. H. (ED.) (2005). Neuropsychology of timing and time perception [Special issue]. Brain \& Cognition, 58(1). doi:10.1016/j.bandc .2004 .09 .004

Meck, W. H., \& Benson, A. M. (2002). Dissecting the brain's internal clock: How frontal-striatal circuitry keeps time and shifts attention. Brain \& Cognition, 48, 195-211. doi:10.1006/brcg.2001.1313

Miller, N., \& McAuley, J. D. (2005). Tempo sensitivity in isochronous tone sequences: The multiple-look model revisited. Perception \& Psychophysics, 67, 1150-1160.

Mitsudo, T., Nakajima, Y., Remijn, G. B., Takeichi, H., Goto, Y., \& ToBimatsu, S. (2009). Electrophysiological evidence of auditory temporal perception related to the assimilation between two neighboring time intervals. NeuroQuantology, 7, 114-127.

Monfort, V., \& Pouthas, V. (2003). Effects of working memory demands on frontal slow waves in time-interval reproduction tasks in humans. Neuroscience Letters, 343, 195-199.

Morrone, M. C., Ross, J., \& Burr, D. (2005). Saccadic eye movements cause compression of time as well as space. Nature Neuroscience, $\mathbf{8}$, 950-954. doi:10.1038/nn1488

Nakajima, Y., ten Hoopen, G., Sasaki, T., Yamamoto, K., Kadota, M., Simons, M., \& Suetomi, D. (2004). Time-shrinking: The process of unilateral temporal assimilation. Perception, 33, 1061-1079. doi:10.1068/p5061

N'Diaye, K., Ragot, R., Garnero, L., \& Pouthas, V. (2004). What is common to brain activity evoked by the perception of visual and auditory filled durations? A study with MEG and EEG corecordings. Cognitive Brain Research, 21, 250-268. doi:10.1016/ j.cogbrainres.2004.04.006

Nenadic, I., Gaser, C., Volz, H. P., Rammsayer, T., Hager, F., \& SAUER, H. (2003). Processing of temporal information and the basal ganglia: New evidence from fMRI. Experimental Brain Research, 148, 238-246.

Nichelli, P., Always, D., \& Grafman, J. (1996). Perceptual timing in cerebellar degeneration. Neuropsychologia, 34, 863-871. doi:10.1016/ 0028-3932(96)00001-2

Ogden, R. S., Wearden, J. H., \& Jones, L. A. (2008). Double standards: Memory loading in temporal reference memory. Journal of Experimental Psychology: Human Perception \& Performance, 34, 1524-1544. doi:10.1080/02724990344000088

Ono, F., \& KitaZawa, S. (2010). Shortening of subjective tone intervals followed by repetitive tone stimuli. Attention, Perception, \& Psychophysics, 72, 492-500.

ORnSTeIn, R. (1969). On the experience of time. New York: Penguin.

Pariyadath, V., \& Eagleman, D. (2007). The effect of predictability on subjective duration. PLOS ONE, 11, e1264. doi:10.1371/journal .pone. 0001264

Penney, T. B., Gibbon, J., \& Meck, W. H. (2000). Differential effects of auditory and visual signals on clock speed and temporal memory. Journal of Experimental Psychology: Human Perception \& Performance, 26, 1770-1787. doi:10.1037/0096-1523.26.6.1770

Penney, T. B., Gibbon, J., \& Meck, W. H. (2008). Categorical scaling of duration bisection in pigeons (Columba livia), mice (Mus musculus), and humans (Homo sapiens). Psychological Science, 19, 1103-1109. doi:10.1111/j.1467-9280.2008.02210.x

Penney, T. B., \& Vaitilingam, L. (2008). Imaging time. In S. Grondin (Ed.), Psychology of time (pp. 261-294). Bingley, U.K.: Emerald Group.

Perret-Clermont, A.-N. (Ed.) (2005). Thinking time. Göttingen: Hogrefe \& Huber.

Pfeuty, M., Ragot, R., \& Pouthas, V. (2003a). Processes involved in tempo perception: A CNV analysis. Psychophysiology, 40, 69-76. doi:10.1111/1469-8986.00008

Pfeuty, M., Ragot, R., \& Pouthas, V. (2003b). When time is up: CNV time course differentiates the roles of the hemispheres in the discrimination of short tone durations. Experimental Brain Research, 151, 372-379.

Pfeuty, M., Ragot, R., \& Pouthas, V. (2008). Brain activity during interval timing depends on sensory structure. Brain Research, 1024, 112-117. doi:10.1016/j.brainres.2008.01.022

Phillips, D. P., \& Hall, S. E. (2002). Auditory temporal gap detection for noise markers with partially overlapping and non-overlapping spectra. Hearing Research, 174, 133-141.

PöPPEL, E. (1997). A hierarchical model of temporal perception. Trends in Cognitive Sciences, 1, 56-61. doi:10.1016/S1364-6613(97)01008-5

PöPPEL, E. (2004). Lost in time: A historical frame, elementary processing units and the 3-second window. Acta Neurobiologiae Experimentalis, 64, 295-301.

Pouthas, V., Garnero, L., Ferrandez, A.-M., \& Renault, B. (2000). ERPs and PET analysis of time perception: Spatial and temporal brain mapping during visual discrimination tasks. Human Brain Mapping, 10, 49-60. doi:10.1002/(SICI) 1097-0193(200006)10:2<49::AID -HBM10>3.0.CO;2-8

Pouthas, V., George, N., Poline, J.-B., Pfeuty, M., VandeMoorTEELE, P.-F., Hugueville, L., ET AL. (2005). Neural network involved in time perception: An fMRI study comparing long and short interval estimation. Human Brain Mapping, 25, 433-441. doi:10.1002/ hbm.20126

Predebon, J. (1996). The effects of active and passive processing of interval events on prospective and retrospective time estimates. Acta Psychologica, 94, 41-58. doi:10.1016/0001-6918(95)00044-5

QuENÉ, H. (2007). On the just noticeable difference for tempo in speech. Journal of Phonetics, 35, 353-362. doi:10.1016/j.wocn.2006.09.001

RAMMSAYER, T. H. (2008). Neuropharmacological approaches to human timing. In S. Grondin (Ed.), Psychology of time (pp. 295-320). Bingley, U.K.: Emerald Group.

RAMmSAYER, T. H., \& LiMA, S. D. (1991). Duration discrimination of filled and empty auditory intervals: Cognitive and perceptual factors. Perception \& Psychophysics, 50, 565-574.

Rammsayer, T. [H.], \& UlRich, R. (2001). Counting models of temporal discrimination. Psychonomic Bulletin \& Review, 8, 270-277.

RAMmSAYer, T. [H.], \& UlRich, R. (2005). No evidence for qualitative difference in the processing of short and long temporal intervals. Acta Psychologica, 120, 141-171.

RaO, S. M., MaYer, A. R., \& Harrington, D. L. (2001). The evolution of brain activation during temporal processing. Nature Neuroscience, 4, 317-323. doi:10.1038/85191

Rattat, A.-C., \& Droit-Volet, S. (2005). The long-term retention of time: A developmental study. Quarterly Journal of Experimental Psychology, 58B, 163-176.

Rattat, A.-C., \& Droit-Volet, S. (2007). Implicit long-term memory for duration in young children. European Journal of Cognitive Psychology, 19, 271-285. doi:10.1080/09541440600834647

Rau, P.-L. P., Shu-Yun, P., \& Chin-Chow, Y. (2006). Time distortion for expert and novice online game players. CyberPsychology \& Behavior, 9, 396-403. doi:10.1089/cpb.2006.9.396

REPP, B. H. (2005). Sensorimotor synchronization: A review of the tapping literature. Psychonomic Bulletin \& Review, 12, 969-992.

RoBERTS, W. A. (2008). Can animals cognitively travel to the past and future? In S. Grondin (Ed.), Psychology of time (pp. 322-344). Bingley, U.K.: Emerald Group.

Robertson, S., Zelaznik, H., Lantero, D., Gadacz, K., SpenCER, R., Doffin, J., \& SchneidT, T. (1999). Correlations for timing consistency among tapping and drawing tasks: Evidence against a single timing process for motor control. Journal of Experimental Psychology: Human Perception \& Performance, 25, 1316-1330. doi:10.1037/0096-1523.25.5.1316

RoECKELEIN, J. E. (2000). The concept of time in psychology: A resource book and annotated bibliography. Westport, CT: Greenwood.

RoECKELEIN, J. E. (2008). History of conceptions and accounts of time and early time perception research. In S. Grondin (Ed.), Psychology of time (pp. 1-50). Bingley, U.K.: Emerald Group.

Rosenbaum, D. A. (2002). Time, space, and short-term memory. Brain \& Cognition, 48, 52-65. doi:10.1006/brcg.2001.1303 
Roussel, M.-E., Grondin, S., \& Killeen, P. (2009). Spatial effects on temporal categorization. Perception, 38, 748-762.

Roy, M. M., \& Christenfeld, N. J. S. (2008). Effect of task length on remembered and predicted duration. Psychonomic Bulletin \& Review, 15, 202-207. doi:10.3758/PBR.15.1.202

Roy, M. M., Christenfeld, N. J. S., \& McKenzie, C. R. M. (2005). Underestimation of future duration: Memory incorrectly used or memory bias? Psychological Bulletin, 131, 738-756. doi:10.1037/0033 $-2909.131 .5 .738$

RuBIA, K. (2006). The neural corrolates of timing functions. In J. Glicksohn \& M. S. Myslobodsky (Eds.), Timing the future: The case for a time-based prospective memory (pp. 213-238). River Edge, NJ: World Scientific Publishing.

Sarrazin, J.-C., Giraudo, M.-D., Pailhous, J., \& Bootsma, R. J. (2004). Dynamics of balancing space and time in memory: Tau and kappa effects revisited. Journal of Experimental Psychology: Human Perception \& Performance, 30, 411-430. doi:10.1037/0096-1523 30.3.411

Sarrazin, J.-C., Giraudo, M.-D., \& Pittenger, J. B. (2007). Tau and kappa effects in physical space: The case of audition. Psychological Research, 71, 201-218. doi:10.1007/s00426-005-0019-1

SchöNer, G. (2002). Timing, clocks, and dynamical systems. Brain \& Cognition, 48, 31-51. doi:10.1006/brcg.2001.1302

Smith, A., Taylor, E., Lidzba, K., \& Rubia, K. (2003). A right hemispheric frontocerebellar network for time discrimination of several hundreds of milliseconds. NeuroImage, 20, 344-350.

Smith, J. G., Harper, D. N., Gittings, D., \& Abernethy, D. (2007). The effect of Parkinson's disease on time estimation as a function of stimulus duration range and modality. Brain \& Cognition, 64, 130143. doi:10.1016/j.bandc.2007.01.005

Spencer, R. M. C., \& ZelazniK, H. N. (2003). Weber (slope) analyses of timing variability in tapping and drawing tasks. Journal of Motor Behavior, 35, 371-382.

Spencer, R. M. C., Zelaznik, H. N., Diedrichsen, J., \& Ivry, R. B. (2003). Disrupted timing of discontinuous but not continuous movements by cerebellar lesions. Science, 300, 1437-1439.

Staddon, J. E. R., \& Higa, J. J. (1996). Multiple time scales in simple habituation. Psychological Review, 103, 720-733. doi:10.1037/0033 -295X.103.4.720

Staddon, J. E. R., \& Higa, J. J. (1999). Time and memory: Towards a pacemaker-free theory of interval timing. Journal of the Experimental Analysis of Behavior, 71, 215-251. doi:10.1901/jeab.1999.71-215

Strathman, A., \& JoIreman, J. (EDS.) (2005). Understanding behavior in the context of time. Mahwah, NJ: Erlbaum

Szelag, E., \& Wittmann, M. (EDS.) (2004). Time, cognition, thinking [Special issue]. Acta Neurobiologiae Experimentalis, 64(3).

TALlAL, P. (2003). Language learning disabilities: Integrating research approaches. Current Directions in Psychological Science, 12, 206211. doi:10.1046/j.0963-7214.2003.01263.x

TALlaL, P. (2004). Improving language and literacy is a matter of time. Nature Reviews Neuroscience, 5, 721-728. doi:10.1038/nrn1499

TARLACI, S. (ED.) (2009). Time, timing, and the brain [Special issue]. NeuroQuantology, 7

ten Hoopen, G., Miyauchi, R., \& Nakajima, Y. (2008). Time-based illusions in the auditory mode. In S. Grondin (Ed.), Psychology of time (pp. 139-188). Bingley, U.K.: Emerald Group.

Thaut, M. H. (2005). Rhythm, music and the brain: Scientific foundations and clinical applications. New York: Taylor \& Francis.

Thomas, K. E., Handley, S. J., \& Newstead, S. E. (2007). The role of prior task experience in temporal misestimating. Quarterly Journal of Experimental Psychology, 60, 230-240.

Tobin, S., Bisson, N., \& Grondin, S. (2010). An ecological approach to prospective and retrospective timing of long durations: A study involving gamers. PLoS ONE, 5(2), e9271. doi:10.1371/journal pone. 0009271

Tobin, S., \& Grondin, S. (2009). Video games and the perception of very long durations by adolescents. Computers in Human Behavior, 25, 554-559. doi:10.1016/j.chb.2008.12.002

Toplak, M. E., Dockstader, C., \& TAnNock, R. (2006). Temporal information processing in ADHD: Findings to date and new methods. Journal of Neuroscience Methods, 151, 15-26.

Tracy, J. I., Faro, S. H., Mohamed, F. B., Pinsk, M., \& Pinus, A. (2000). Functional localization of a "time keeper" function separate from attentional resources and task strategy. NeuroImage, 11, 228242

Tregellas, J. R., Davalos, D. B., \& Rojas, D. C. (2006). Effect of task difficulty on the functional anatomy of temporal processing. NeuroImage, 32, 307-315

Treisman, M. (1963). Temporal discrimination and the indifference interval: Implications for a model of the "internal clock." Psychological Monographs, 77(Whole no. 576)

Treisman, M., Faulkner, A., Naish, P. L. N., \& Brogan, D. (1990). The internal clock: Evidence for a temporal oscillation underlying time perception with some estimates of its characteristic frequency. Perception, 19, 705-743.

Tse, C.-Y., \& Penney, T. B. (2006). Preattentive timing of empty intervals is from marker offset to onset. Psychophysiology, 43, 172-179. doi:10.1111/j.1469-8986.2006.389.x

Tse, P. U., Intriligator, J., Rivest, J., \& Cavanagh, P. (2004). Attention and the subjective expansion of time. Perception \& Psychophysics, 66, 1171-1189.

Tulving, E. (2002). Chronesthesia: Conscious awareness of subjective time. In D. T. Stuss \& R. T. Knight (Eds.), Principles of frontal lobe function (pp. 311-325). New York: Oxford University Press.

Ulrich, R., Nitschke, J., \& Rammsayer, T. (2006). Crossmodal temporal discrimination: Assessing the predictions of a general pacemaker-counter model. Perception \& Psychophysics, 68, 11401152.

Vicario, G. B. (2005). Il tempo. Saggio di psicologia sperimentale [On time: An essay in experimental psychology]. Bologna, Italy: Il Mulino.

Volz, H.-P., Nenadic, I., Gaser, C., Rammsayer, T., Hager, F., \& SAuER, H. (2001). Time estimation in schizophrenia: An fMRI study at adjusted levels of difficulty. NeuroReport, 12,313-316. doi:10.1097 00001756-200102120-00026

WACKERMANN, J. (2007). Inner and outer horizons of time experience. Spanish Journal of Psychology, 10, 20-32.

WACKERMANN, J., \& EHM, W. (2006). The dual klepsydra model of internal time representation and time reproduction. Journal of Theoretical Biology, 239, 482-493. doi:10.1016/j.jtbi.2005.08.024

Walker, J. T., \& ScotT, K. J. (1981). Auditory-visual conflicts in the perceived duration of lights, tones, and gaps. Journal of Experimental Psychology: Human Perception \& Performance, 7, 1327-1339. doi:10.1037/0096-1523.7.6.1327

Wallace, M., \& Rabin, A. I. (1960). Temporal experience. Psychological Bulletin, 57, 213-235. doi:10.1037/h0041410

WEARDEN, J. H. (1992). Temporal generalization in humans. Journal of Experimental Psychology: Animal Behavior Processes, 18, 134-144. doi:10.1037/0097-7403.18.2.134

WEARDEN, J. H. (2003). Applying the scalar timing model to human time psychology: Progress and challenges. In H. Helfrich (Ed.), Time and mind II (pp. 21-39). Göttingen: Hogrefe \& Huber.

Wearden, J. H. (2004). Decision processes in models of timing. Acta Neurobiologiae Experimentalis, 64, 303-317.

Wearden, J. H., Edwards, H., Fakhri, M., \& Percival, A. (1998) Why "sounds are judged longer than lights": Application of a model of the internal clock in humans. Quarterly Journal of Experimental Psychology, 51B, 97-120.

WEARDEN, J. H., \& LEJEUNE, H. (2008). Scalar properties in human timing: Conformity and violations. Quarterly Journal of Experimental Psychology, 61, 569-587. doi:10.1080/17470210701282576

Wearden, J. H., Norton, R., Martin, S., \& Montford-Bebb, O. (2007). Internal clock processes and the filled-duration illusion. Journal of Experimental Psychology: Human Perception \& Performance, 33, 716-729. doi:10.1037/0096-1523.33.3.716

Wearden, J. H., Smith-Spark, J. H., Cousins, R., Edelstyn, N. M. J., Cody, F. W. J., O'Boyle, D. J. (2008). Stimulus timing by people with Parkinson's disease. Brain \& Cognition, 67, 264-279. doi:10.1016/ j.bandc. 2008.01 .010

WING, A. M. (2002). Voluntary timing and brain function: An information processing approach. Brain \& Cognition, 48, 7-30. doi:10.1006/ brcg.2001.1301

Wing, A. M., \& Kristofferson, A. B. (1973). Response delays and the timing of discrete motor responses. Perception \& Psychophysics, 14, 5-12.

Wittmann, M., \& Van Wassenhove, V. (EDS.) (2009). The experience of time: Neural mechanisms and the interplay of emotion, cognition 
and embodiment [Special issue]. Philosophical Transactions of the Royal Society B, 364(1525). doi:10.1098/rstb.2009.0025

Woodrow, H. (1934). The temporal indifference interval determined by the method of average error. Journal of Experimental Psychology, 17, 167-188.

Yarrow, K., Haggard, P., Heal, R., Brown, P., \& Rothwell, J. C. (2001). Illusory perceptions of space and time preserve cross-saccadic perceptual continuity. Nature, 414, 302-305. doi:10.1038/35104551

YARRow, K., \& Rothwell, J. C. E. (2003). Manual chronostasis: Tactile perception precedes physical contact. Current Biology, 13, 13341339. doi:10.1016/S0960-9822(03)00413-5

ZAKAY, D. (1993). Time estimation methods-Do they influence prospective duration estimates? Perception, 22, 91-101. doi:10.1068/ p220091

ZAKAY, D. (1998). Attention allocation policy influences prospective timing. Psychonomic Bulletin \& Review, 5, 114-118.

ZakaY, D., \& Block, R. A. (1997). Temporal cognition. Current Directions in Psychological Science, 6, 12-16. doi:10.1111/1467-8721 .ep11512604

ZAKAY, D., \& Block, R. A. (2004). Prospective and retrospective duration judgments: An executive-control perspective. Acta Neurobiologiae Experimentalis, 64, 319-328.

ZeILER, M. D. (1998). On sundials, springs, and atoms. Behavioural Processes, 44, 89-99. doi:10.1016/S0376-6357(98)00042-4

ZeILER, M. D. (1999). Time without clocks. Journal of the Experimental Analysis of Behavior, 71, 288-291. doi:10.1901/jeab.1999.71-288

Zelaznik, H. N., SPencer, R. M. [C.], \& Doffin, J. G. (2000). Temporal precision in tapping and circle drawing movements at preferred rates is not correlated: Further evidence against timing as a general purpose ability. Journal of Motor Behavior, 32, 193-199.

ZelazniK, H. N., SPencer, R. M. C., \& Ivry, R. B. (2002). Dissociation of explicit and implicit timing in repetitive tapping and drawing movements. Journal of Experimental Psychology: Human Perception \& Performance, 28, 575-588. doi:10.1037/0096-1523.28.3.575

Zelaznik, H. N., Spencer, R. M. C., \& Ivry, R. B. (2008). Behavioral analysis of human movement timing. In S. Grondin (Ed.), Psychology of time (pp. 233-260). Bingley, U.K.: Emerald Group.

Zimbardo, P., \& Boyd, J. (1999). Putting time in perspective: A valid, reliable individual-differences metric. Journal of Personality \& Social Psychology, 77, 1271-1288. doi:10.1037/0022-3514.77.6.1271

\section{NOTES}

1. A large body of work on speech and language impairment, as well as on reading impairment, relates temporal processing to time order judgments - that is, the ability to report, when presented with two sensory signals, which one occurred first (Boets, Wouters, van Wieringen, \& Ghesquière, 2006; Edwards et al., 2004; Grondin et al., 2007; Tallal, 2003, 2004). Indeed, the field of temporal order judgment (TOJ) and the impression of successiveness has a long history and is not restricted to speech and language research. In a classic 1961 article, Hirsh and Sherrick adopted a multimodal approach for estimating temporal order thresholds (the minimum time interval required to perceive the order correctly). Describing the various contexts used to study TOJ and their impact on threshold estimates is a very complex task that is far beyond the scope of this review. Finally, note that, nowadays, some researchers who are interested in attention and multisensory processing also use a TOJ task.
2. There are several other developmental issues related to psychological time (for a fine review, see Friedman, 2008), some of which are linked to contemporary issues concerning the functioning of an internal clock (Droit-Volet, Meck, \& Penney, 2007; Droit-Volet, Wearden, \& Delgado, 2007; McAuley, Jones, Holub, Johnston, \& Miller, 2006; McCormack, Wearden, Smith, \& Brown, 2005; Rattat \& Droit-Volet, 2005, 2007; see also Block, Zakay, \& Hancock, 1999).

3. It is worth mentioning that the approach referred to as interval production may also refer to something else. Researchers who are interested in timing in motor behavior often use a series of continuous finger taps for producing intervals - a series that is usually preceded by a synchronization phase with auditory signals (Wing \& Kristofferson, 1973; Zelaznik et al., 2002, 2008). These researchers are most often interested in the variability of the intertap intervals. Wing and Kristofferson proposed to submit the series of produced intervals to an autocorrelation analysis - that is, to an analysis revealing the influence exerted on a given production by the preceding produced intervals. This analysis is used to sort out the part of variability that belongs to each of two components: the temporal one that is attributed to a clock mechanism, and the motor one that is associated with the implementation of the intervals with finger taps. Finally, note that other researchers are interested mainly in timing in music perception and production, and they emphasize more specifically the ability to synchronize a finger with sensory events (synchronization task; for a review, see Repp, 2005).

4 . The value of the indifference interval is highly debatable. For instance, it is $625 \mathrm{msec}$ in Woodrow (1934). The term indifference interval (or indifference point) is attributed to Karl von Vierordt, and the tendency to overestimate short intervals and to underestimate long intervals is known as Vierordt's law (see Lejeune \& Wearden, 2009). This could be seen as a central tendency effect, or as another instance of the adaptationlevel theory (Helson, 1964). Generally speaking, the value of an indifference interval varies with the global context of an experiment - that is, with the mean (arithmetic or geometric) intervals and their distribution range (M. R. Jones \& McAuley, 2005).

5. Note that there could be some social training for the 1-sec unit. Some microwave ovens signal the end of an operation with a series of five brief auditory sounds every second; furthermore, at some intersections, a countdown in seconds is used to indicate the period during which pedestrians have priority.

6 . The functional relationship between the variability (or difference threshold) and the magnitude of a stimulus (or of an interval, in the case of time) is known as the Weber discrimination law (Killeen \& Weiss, 1987). In its strict form, this relationship is linear, and the variability to magnitude ratio is constant-Weber's constant, or Weber's fraction.

7. Most studies referred to in this section are based on the presentation of single intervals, but it should be kept in mind that single intervals are judged in a global context in which multiple trials are completed and, therefore, that short or long responses depend on the properties of a given task, block of trials, and session (M. R. Jones \& McAuley, 2005).

8. It is plausible that a clock device is located, like the cerebellum, at a subcortical level. For instance, this hypothesis has been put forward on the basis of data from a split brain (no connection between cerebral hemispheres) patient (Handy, Gazzaniga, \& Ivry, 2003): The output of a subcortical internal clock would be projected, by way of a subcortical commissure, to each cerebral hemisphere (Marzi, 2004).

9. The putamen and caudate nucleus form the striatum.

10. The "start-timing" or "stop-timing" signals could be linked to the switch process that was described earlier. 


\section{APPENDIX}

The value of the Weber fraction for time varies with the conditions of an experiment. In the following example, which is based on the comparison method, the standard duration ( $\mathrm{St}$ ) was always $500 \mathrm{msec}$, and the eight comparison intervals (Co) varied from 395 to $605 \mathrm{msec}$ (Grondin \& McAuley, 2009). Three fundamental aspects varied in this study: the number of intervals presented (one or four) in the first or second sequence (see Figure A1), the sensory modality (auditory [A] or visual [V]) of the signals marking the intervals, and the order of presentation of St and Co. Each sensory signal lasted $20 \mathrm{msec}$, and the interstimulus interval lasted $1 \mathrm{sec}$.

Sequence 1

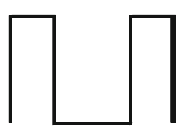

$\square$
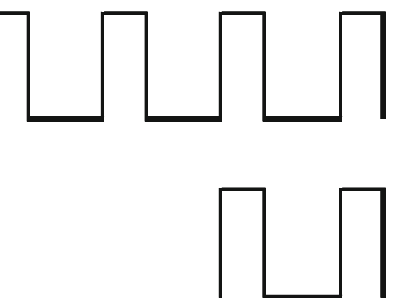

ISI

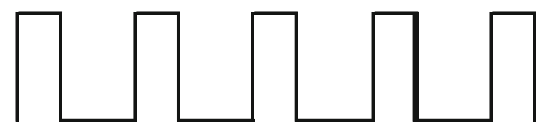

ISI

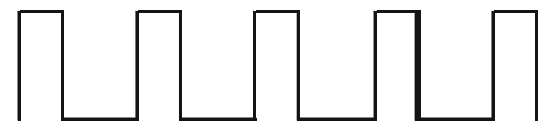

Sequence 2

ISI

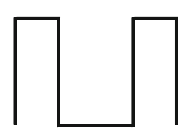

ISI
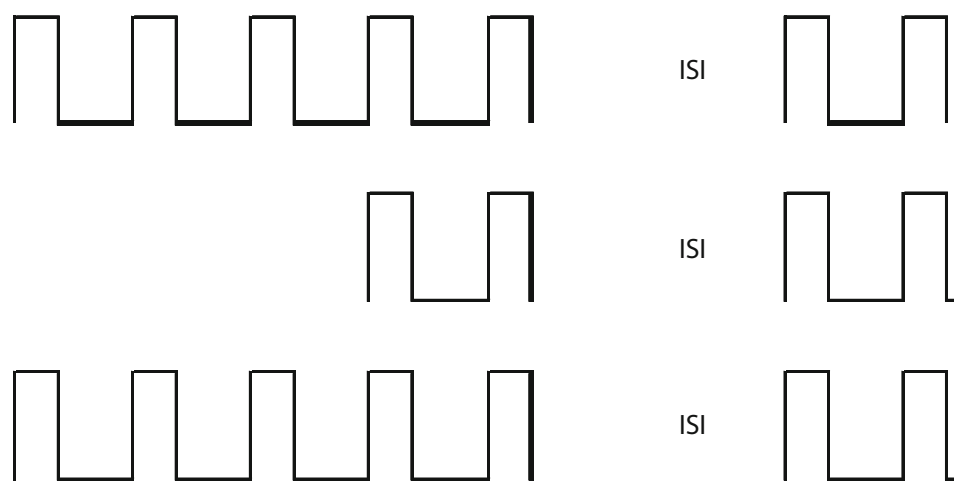

Figure A1. Schematic of the method in Grondin and McAuley (2009), in which there were two or five tones in Sequence 1 and Sequence 2, marking either one or four intervals. ISI, interstimulus interval.

The results in each condition are reported in Table A1.

Table A1

Mean Weber Fraction for Each Experimental Condition in Grondin and McAuley (2009)

\begin{tabular}{|c|c|c|c|c|c|}
\hline \multicolumn{2}{|c|}{ Number of Intervals } & \multicolumn{2}{|c|}{ Sensory Modalities } & \multicolumn{2}{|c|}{ Weber Fraction $(\%)$} \\
\hline Sequence 1 & Sequence 2 & Sequence 1 & Sequence 2 & St-Co & $\mathrm{Co}-\mathrm{St}$ \\
\hline 1 & 1 & A & A & 6.79 & 9.67 \\
\hline 4 & 1 & $\mathrm{~A}$ & A & 5.95 & 9.86 \\
\hline 1 & 4 & A & A & 5.34 & 8.37 \\
\hline 4 & 4 & A & A & 4.11 & 6.72 \\
\hline 1 & 1 & V & $\mathrm{V}$ & 13.23 & 27.90 \\
\hline 4 & 1 & $\mathrm{~V}$ & $\mathrm{~V}$ & 14.25 & 23.13 \\
\hline 1 & 4 & $\mathrm{~V}$ & $\mathrm{~V}$ & 10.00 & 26.99 \\
\hline 4 & 4 & V & $\mathrm{V}$ & 7.05 & 15.67 \\
\hline 1 & 1 & A & $\mathrm{V}$ & 11.54 & 16.60 \\
\hline 4 & 1 & A & $\mathrm{V}$ & 11.73 & 9.69 \\
\hline 1 & 4 & A & $\mathrm{V}$ & 8.29 & 13.27 \\
\hline 4 & 4 & A & $\mathrm{V}$ & 7.91 & 9.42 \\
\hline 1 & 1 & $\mathrm{~V}$ & A & 12.10 & 16.27 \\
\hline 4 & 1 & V & A & 10.04 & 11.60 \\
\hline 1 & 4 & V & A & 8.65 & 13.98 \\
\hline 4 & 4 & V & A & 7.38 & 9.95 \\
\hline
\end{tabular}

Note-St, standard duration; Co, comparison interval.

Note that the Weber fractions are generally reported to be higher for very brief durations. For instance, in an interval discrimination study in which participants are asked to detect anisochrony (the deviation of a tone) in sequences of tones, the Weber fractions are about $6 \%-8 \%, 11 \%-12 \%$, and $20 \%$, respectively, for standard intervals (interonset intervals) equal to 200, 100, and $50 \mathrm{msec}$ (Hirsh, Monahan, Grant, \& Singh, 1990). 